\title{
Geochemical Association Rules of Elements Mined using Clus- tered Events of Spatial Auto-correlation: A Case Study in the Chahanwusu River Area, Qinghai Province, China
}

\author{
Baoyi Zhang ${ }^{1,2}$, Zhengwen Jiang ${ }^{2}$, Yiru Chen ${ }^{2}$, Nanwei Cheng ${ }^{2}$, Umair Khan ${ }^{2}$ and Jiqiu Deng ${ }^{1,2, *}$ \\ 1 Key Laboratory of Metallogenic Prediction of Nonferrous Metals and Geological Environment Monitoring \\ (Ministry of Education), Central South University, Changsha 410083, China; zhangbaoyi@csu.edu.cn (B.Z.) \\ 2 School of Geosciences and Info-Physics, Central South University, Changsha 410083, China; jiang- \\ zhengwen@csu.edu.cn (Z.J.); $195011096 @$ csu.edu.cn (Y.C.); 215011050@csu.edu.cn (N.C.); \\ Umair77@csu.edu.cn (U.K.) \\ * Correspondence: csugis@csu.edu.cn; Tel.: +86-731-88877676 (J.D.)
}

\begin{abstract}
The spatial distribution of elements can be regarded as a numerical field of concentration values with a continuous spatial coverage. An active area of research is to discover geologically meaningful relationships among elements from their spatial distribution. To solve this problem, we propose an association rule mining method based on clustered events of spatial auto-correlation and applied it to the polymetallic deposits of the Chahanwusu River area, Qinghai Province, China. The elemental data for stream sediments were first clustered into HH (high-high), LL (low-low), HL (high-low), and LH (low-high) groups by using local Moran's I clustering map (LMIC). Then the Apriori algorithm was used to mine the association rules among different elements in these clusters. More than $86 \%$ of the mined rule points are located within $1000 \mathrm{~m}$ of faults and near known ore occurrences, and occur in the upper reaches of the stream and catchment areas. In addition, we found that the Indosinian granodiorite is enriched in sulfophile elements, e.g., $\mathrm{Zn}, \mathrm{Ag}$ and $\mathrm{Cd}$, and the Variscan granite quartz diorite $\left(\mathrm{P}_{1} \gamma \delta \mathrm{o}\right)$ coexists with $\mathrm{Cu}$ and associated elements. Therefore, the proposed algorithm is an effective method for mining co-existence patterns of elements and provides an insight into their enrichment mechanisms.
\end{abstract}

Keywords: Concentration field; Spatial auto-correlation; Association rules; Apriori algorithm; Element co-occurrence

\section{Introduction}

Spatial auto-correlation analysis focuses on the similarity of attributes as well as spatial similarity between one geological entity and adjacent entities. The spatial distribution of concentrations of elements can be regarded as a numerical field with a continues spatial coverage, which can be characterized by using the spatial auto-correlation among different elements. Korobova and Romanov (2009) stressed that the nonrandom characteristics and spatial structure of geochemical data depend on the concentration field [1]. The analysis of the concentration field includes comparing samples to recognize anomalies and using the spatial correlation among elements to explain geochemical processes. Geological interactions between elements result in mutual influence and restriction. Therefore, it is necessary to consider spatial auto- and cross-correlation in geochemical studies. The concentrations and spatial association of different elements are usually related to parent lithostrata. Therefore, it is of great significance to study the distribution, enrichment, and relationships among different elements to understand regional magmatism and ore-forming process [2].

Tobler (1970) proposed the first law of geography: everything is related to everything else, but near things are more related to distant things[3]. The measurement of spatial 
auto-correlation includes global and local indicators. The global indicators reveal the spatial pattern of the whole region and reflect the global characteristics. In contrast, local indicators measure the relationship between each location and its neighbors to reveal more detailed local spatial patterns. Global metrics include Moran's I [4] and Geary's C [5]. Improvements in spatial theory and statistical tests have made Moran's I and Geary's C become the most widely used global indicators [6-8]. Based on Moran's I, Cliff and Ord (1981) also proposed a simple spatio-temporal auto-correlation indicator form $I_{s-t}$ [8]. Getis and Ord $(1992,1995)$ proposed global $G$ statistic and local $G^{*}$ statistic $[9,10]$. Anselin (1995) developed local indicators of spatial association (LISA), including local Moran's I and local Geary's C [11]. Boots and Okabe (2007) proposed the concept of local spatial statistical analysis (LoSSA) both as an integrative structure for existing methods and as a framework that facilitates the development of new local and global statistics [12]. Anselin (2019) extended the application of the local Geary's C statistic to a multivariate context. According to the characteristics of experimental data, each local auto-correlation indicator has its advantages and disadvantages [13]. Spatial auto-correlation indicators have been used in the fields of environmental science, regional economy, identification of diseases and mortality, and detection of geochemical anomalies [14-18].

The spatial pattern of the concentration field is caused by different geological processes [19]. The concentration field reflects the migration of elements and the spatio-temporal distribution of various elements. Therefore, both the spatial characteristics of a single element and the spatial relationship among multiple elements need to be considered.

For a long time, the identification and evaluation of geochemical anomalies has been a key issue in the field of geochemical exploration [20-22]. A geochemical anomaly is the enrichment or dilution of elements. The enriched area often has high mineral resource potential $[23,24]$. Geologists seek to use the spatial pattern to distinguish an anomaly from the background. For many years, various statistical methods, such as mean $\pm 2 \times$ standard deviations [25], probability graphs [26], univariate analysis [27], multivariate analysis [28,29], logistic regression [30,31], weights of evidence [32-34], fractal/multifractal models [35-37], and geostatistics [38,39] have been used to identify geochemical anomalies. In recent years, machine learning methods have been used in geological prospecting. These methods include support vector machines [40,41], random forests [42,43], Bayesian networks [44-46], and deep autoencoder networks [47].

Some small ore deposits or occurrences are overlooked in actual mineral prospecting if the association rules among elements are not considered [19]. How to efficiently delineate the metallogenic target area has become one of the main objectives of geochemical exploration. Nguyen et al. (2014) found that local Moran's I could better detect the spatial clustering of elements in stream sediments on a small spatial scale than classical statistics, and local $\mathrm{G}^{*}$ is suitable for detecting high clustered on a large scale [48]. Wang et al. (2015) used geostatistics, fractal and spatial auto-correlation methods to study the spatial characteristics of geochemical data for stream sediments in southwest Fujian, and concluded that the spatial auto-correlation method delineates the geochemical anomaly [49]. Ji et al. (2017) used local Moran's I to analyze the spatial clustering and outliers of elemental concentrations and extracted geochemical anomalies [50]. Yu et al. (2021) proposed a local correlation coefficient based on spatial neighborhoods to characterize the global distribution of elements [16].

The mutual influence and interaction among different elements produce a spatial pattern [51,52]. The effects of regional geological and geochemical processes can be inferred from the spatial patterns in the concentration field. Therefore, exploring the association rules among different elements is of great significance for understanding geological processes. Association rule mining is one of the branch fields of data mining. The Apriori algorithm can uncover Boolean association rules between itemsets and has been widely used in spatial data mining [53-56]. The Apriori algorithm was proposed by Agrawal et al. (1993), who used it to mine association rules of sales data obtained from a large retailing company [57]. Liu and Zhou (2019) used the Apriori algorithm to derive the anomalies of elements for metallogenic prediction [58]. 
In this paper, we proposed an association rule mining method to study the crosscorrelation of concentration fields based on clustered events of spatial auto-correlation. This method can be used to comprehensively understand the spatial distribution of geochemical concentrations and co-existing of elements. Moreover, we compared the advantages and limitations of bivariate spatial auto-correlation and association rule mining results, and finally explored the relationship of specific geological features with the results of association rule mining.

\section{Study area and data}

\subsection{Geological background}

The Chahanwusu River area $\left(98^{\circ} 15 \mathrm{E}^{\prime}-98^{\circ} 45^{\prime} \mathrm{E}, 35^{\circ} 50^{\prime} \mathrm{N}-36^{\circ} 00^{\prime} \mathrm{N}\right)$ covers approximately $893 \mathrm{~km}^{2}$ in the eastern part of the East Kunlun tectonic belt in Dulan County in central Qinghai Province. The area is a polymetallic belt where one gold deposit, three copper deposits, one lead-zinc deposit two magnetite deposits, and one gem-stone deposit have been found [59]. Figure 1 shows the sketch geological map of the study area [43].

The main faults in the study area are EW, NW, and NE-trending, which constitute the structural framework of the area. NW-trending faults are the most developed, and control the distribution of strata and magmatic rocks. The sedimentary strata in the study area are undeveloped and dispersed. The outcropping strata from old to new are the Paleoproterozoic Baishahe rock Formation $\left(\mathrm{Pt}_{\mathrm{b}} \mathrm{b}\right)$, the late Triassic Elashan Formation (Tзe), the Neogene Guide Group (NG) and Quaternary sediments (Q). Outcrops of intrusive rocks are widespread in the study area, and are dominated by Variscan and Indosinian intrusives.

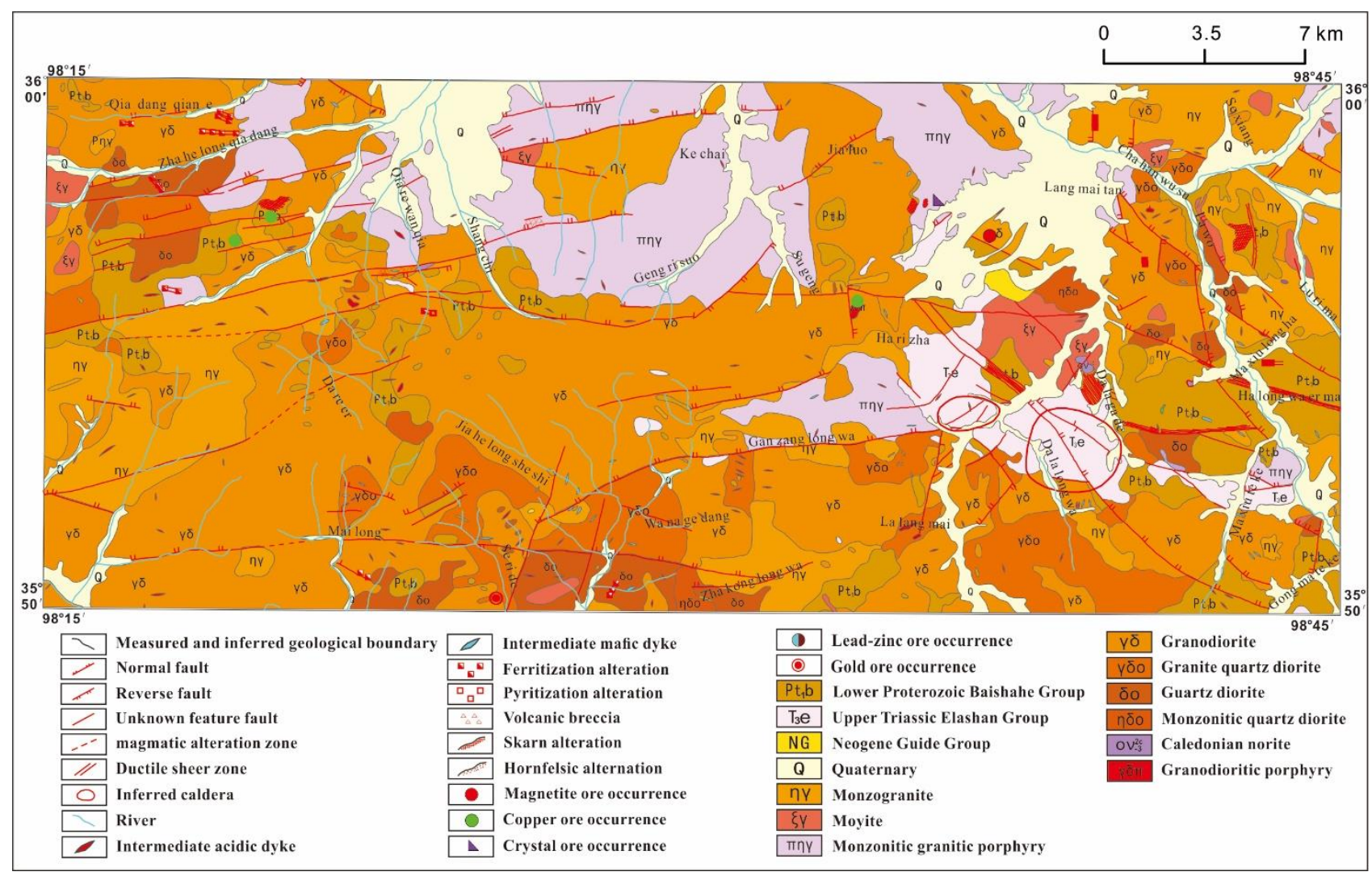

Figure 1. Geological map of the study area [43].

\subsection{Geochemical data}

The datasets used in this study were geochemical analyses of 4959 stream sediment samples taken at a density of 5.55 points per $1 \mathrm{~km}^{2}$ by the Geological Survey Institute of 
Qinghai Province (Figure 2). The concentrations of 15 elements ( $\mathrm{Au}, \mathrm{Sn}, \mathrm{Ag}$, As, Sb, Bi, Co, $\mathrm{Cu}, \mathrm{La}, \mathrm{Pb}, \mathrm{Zn}, \mathrm{W}, \mathrm{Mo}, \mathrm{Nb}$, and $\mathrm{Cd}$ ) were measured in each sample. The methods used to analyze the concentration of heavy metals include atomic emission spectrometry (AES) for $\mathrm{Au}, \mathrm{Ag}$, and $\mathrm{Sn}$, atomic fluorescence spectrometry (AFS) for $\mathrm{As}, \mathrm{Sb}$, and $\mathrm{Bi}$, atomic absorption spectrometry (AAS) for $\mathrm{Cu}, \mathrm{Pb}, \mathrm{Zn}, \mathrm{Co}$, and $\mathrm{Ni}$, and polarography (POL) for $\mathrm{W}$ and Mo.

The elemental concentrations are summarized in Table 1 . The coefficient of variation $(\mathrm{CV})$ is expressed as the ratio of the standard deviation to the mean and is an important parameter that reflects the homogenization of element distribution. The elements with the $\mathrm{CV}>1$ from largest to smallest are $\mathrm{Bi}, \mathrm{W}, \mathrm{Sb}, \mathrm{As}, \mathrm{Ag}, \mathrm{Sn}, \mathrm{Au}, \mathrm{Cu}, \mathrm{Pb}, \mathrm{Mo}$. Larger CV represents more inhomogeneous elemental concentrations. The higher the coefficient of variation, the greater the level of dispersion around the mean.

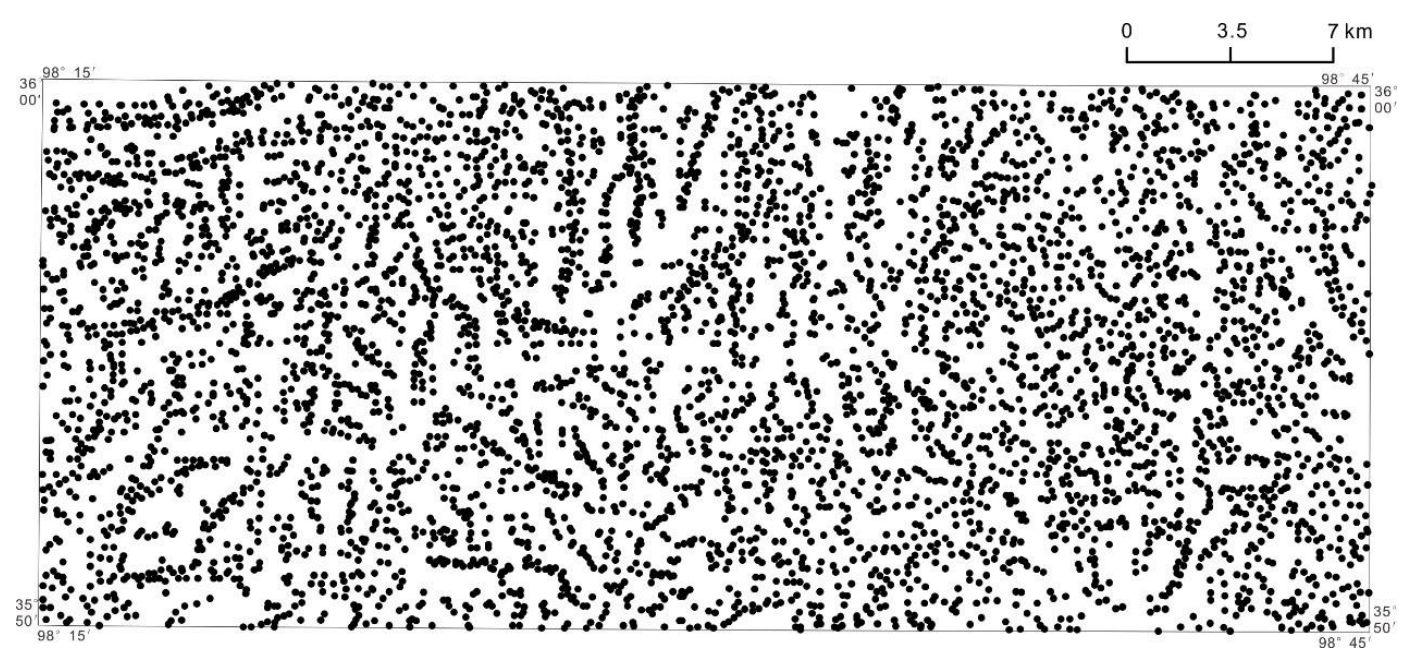

Figure 2. Map of stream sediment geochemical sampling points.

Table 1. Main statistical results of the stream sediment elements in the study area.

\begin{tabular}{ccccccc}
\hline Element & Mean & Median & $\begin{array}{c}\text { Standard } \\
\text { Deviation }\end{array}$ & Skewness & Kurtosis & $\begin{array}{c}\text { Coefficient of } \\
\text { Variation }\end{array}$ \\
\hline $\mathrm{Au}$ & 1.42 & 1.20 & 1.81 & 25.07 & 793.15 & 1.27 \\
$\mathrm{Sn}$ & 2.31 & 1.70 & 3.21 & 10.35 & 134.68 & 1.39 \\
$\mathrm{Ag}$ & 76.31 & 41.00 & 117.35 & 6.77 & 67.02 & 1.54 \\
$\mathrm{As}$ & 13.07 & 8.10 & 21.89 & 13.21 & 303.48 & 1.68 \\
$\mathrm{Sb}$ & 0.82 & 0.47 & 1.45 & 14.56 & 372.59 & 1.88 \\
$\mathrm{Bi}$ & 0.37 & 0.17 & 1.00 & 13.68 & 256.65 & 2.50 \\
$\mathrm{Co}$ & 7.07 & 6.40 & 3.44 & 3.07 & 24.09 & 0.48 \\
$\mathrm{Cu}$ & 16.05 & 12.10 & 20.44 & 15.15 & 330.62 & 1.27 \\
$\mathrm{La}$ & 13.73 & 12.00 & 8.30 & 8.99 & 192.65 & 0.61 \\
$\mathrm{~Pb}$ & 17.00 & 12.80 & 21.29 & 13.35 & 314.69 & 1.25 \\
$\mathrm{Zn}$ & 48.29 & 40.40 & 32.06 & 4.27 & 27.61 & 0.66 \\
$\mathrm{~W}$ & 2.74 & 1.70 & 5.99 & 18.99 & 528.95 & 2.22 \\
$\mathrm{Mo}$ & 1.20 & 0.96 & 1.36 & 9.31 & 117.22 & 1.17 \\
$\mathrm{Nb}$ & 3.93 & 3.30 & 2.26 & 4.53 & 37.90 & 0.59 \\
$\mathrm{Cd}$ & 0.15 & 0.10 & 0.18 & 5.28 & 49.30 & 0.85 \\
\hline $\mathrm{Aug}$ & & & & &
\end{tabular}

Au、 Ag: $10^{-9}$, others: $10^{-6}$.

\section{Methods}

\subsection{Spatial auto-correlation}

3.1.1. Univariate spatial auto-correlation 
Spatial auto-correlation indicates the extent to which one attribute of a feature is influenced by nearby features [60]. Spatial auto-correlation indicators are the sum of the cross product of a similarity matrix $c_{i j}$ and spatial similarity matrix $w_{i j}$, and include global (Eq. 1) and local (Eq. 2) metric indicators [11]. In general form, they are written as

$$
\begin{aligned}
& \Gamma_{g}=\sum_{i=1}^{n} \sum_{j=1}^{n} c_{i j} w_{i j} \\
& \Gamma(i)=\sum_{j=1}^{n} c_{i j} w_{i j}
\end{aligned}
$$

where $n$ is the total numbers of observations, $c_{i j}$ is the self-similarity matrix, and $w_{i j}$ is the spatially weighted matrix.

Global indicators give the degree of spatial association for a single value, and local indicators assess the extent to which observations of similar and dissimilar values are clustered for each location [11]. Different measures of similarity yield different indices for spatial association [11]. For example, using $c_{i j}=\left(x_{i}-\bar{x}\right)\left(x_{j}-\bar{x}\right)$ yields a Moran-like indicator, setting $c_{i j}=\left(x_{i}-x_{j}\right)^{2}$ yields a Geary-like indicator, and setting $c_{i j}=x_{i} x_{j}$ yields a Getis-Ord-like indicator. The corresponding spatial auto-correlation indicators are global Moran's I [4,6-8], Geary's C [5,6,8], and Getis-Ord's G [9], respectively. A global spatial auto-correlation indicator can only reflect the overall spatial trend and auto-correlation of the geographical entity or phenomenon. However, local spatial auto-correlation indicators measure the correlation among various locations and their neighbors to reveal more detailed local spatial patterns. These indicators include local Moran's I [11], Geary's C [11], and Getis-Ord's G [9]. The calculation method of univariate global and local spatial auto-correlation statistics is shown in Table 2.

\begin{tabular}{|c|c|c|c|}
\hline $\begin{array}{l}\text { Spatial auto-correlation } \\
\text { statistics }\end{array}$ & Calculation formula & Remarks & References \\
\hline global Moran's I & $I=\frac{n \sum_{i}^{n} \sum_{j}^{n} w_{i j}\left(x_{i}-\bar{x}\right)\left(x_{j}-\bar{x}\right)}{\left(\sum_{i}^{n} \sum_{j}^{n} w_{i j}\right) \sum_{i}^{n}\left(x_{i}-\bar{x}\right)^{2}}$ & $\begin{array}{l}\text { The range of } I \text { is }[-1,1], I<0 \text { indicates } \\
\text { negative spatial auto-correlation, } I>0 \\
\text { indicates positive spatial auto- } \\
\text { correlation, } I \text { tends to } 0 \text { indicates } \\
\text { spatial random distribution. }\end{array}$ & {$[4,6-8]$} \\
\hline global Geary's C & $C=\frac{(n-1) \sum_{i}^{n} \sum_{j}^{n} w_{i j}\left(x_{i}-x_{j}\right)^{2}}{\left(2 \sum_{i}^{n} \sum_{j}^{m} w_{i j}\right) \sum_{i}^{n}\left(x_{i}-\bar{x}\right)^{2}}$ & $\begin{array}{l}\text { The range of } C \text { is }[0,2], C>1 \text { indicates } \\
\text { negative spatial auto-correlation, } C<1 \\
\text { indicates positive spatial auto- } \\
\text { correlation, } C \text { tends to } 1 \text { indicates } \\
\text { spatial random distribution. }\end{array}$ & {$[5,6,8]$} \\
\hline global Getis-Ord's G & $G=\frac{\sum_{i}^{n} \sum_{j}^{n} w_{i j} x_{i} x_{j}}{\sum_{i}^{n} \sum_{j}^{n} x_{i} x_{j}}$ & $\begin{array}{c}G<\text { mathematical expectation }(\mathrm{ME}) \\
\text { indicates low value clustered, } G>\mathrm{ME} \\
\text { indicates high value clustered, } G \text { tends } \\
\text { to ME indicates spatial random } \\
\text { distribution. }\end{array}$ & [9] \\
\hline local Moran's I & $\begin{array}{c}I(i)=\frac{\left(x_{i}-\bar{x}\right)}{S^{2}} \sum_{j}^{n} w_{i j}\left(x_{j}-\bar{x}\right) \\
S^{2}=\frac{\sum_{i}^{n}\left(x_{i}-\bar{x}\right)^{2}}{n}\end{array}$ & $\begin{array}{l}Z(I(i))<0 \text { indicates negative spatial } \\
\text { auto-correlation, } Z(I(i))>0 \text { indicates } \\
\quad \text { positive spatial auto-correlation, }\end{array}$ & [9] \\
\hline
\end{tabular}

Table 2. Spatial auto-correlation statistics. 
$Z(I(i))$ tends to 0 indicates spatial random distribution.

local Geary's C

$$
C(i)=\frac{1}{S^{2}} \sum_{j}^{n} w_{i j}\left(x_{i}-x_{j}\right)^{2}
$$

$$
S^{2}=\frac{\sum_{i}^{n}\left(x_{i}-\bar{x}\right)^{2}}{n}
$$

local Getis-Ord's G

$$
G(i)=\left(\sum_{j}^{n} w_{i j} x_{j}\right) / \sum_{j}^{n} x_{j}
$$

$Z(C(i))<0$ indicates negative spatial auto-correlation, $Z(C(i))>0$ indicates positive spatial auto-correlation, $Z(C(i))$ tends to 0 indicates spatial random distribution.

$Z(G(i))<0$ indicates negative spatial auto-correlation, $Z(G(i))>0$ indicates positive spatial auto-correlation, random distribution.

$x_{i}$ and $x_{j}$ is the observed value at positions $i$ and $j, x_{j}$ is $x_{i}$ position's neighbor point in a certain distance, $n$ is the total numbers of observations, $\bar{x}$ is the mean value of the observations, $w_{i j}$ is the spatial weight matrix. $Z(\Gamma)=(\Gamma-E(\Gamma)) / \sqrt{\operatorname{VAR}(\Gamma)}, \Gamma$ is a spatial statistic, $E(\Gamma)$ is the mathematical expectation of $\Gamma, \operatorname{VAR}(\Gamma)$ is the variance of $\Gamma$.

To take an example, given the spatial distribution of points in Figure $3 a$, we obtain a distance matrix (Figure 3b) between point pairs, then we get a spatially weighted matrix (Figure 3c) between point pairs according to whether their distance is less than 4 units. According to Figure 3, we find that the global Moran's I value is -0.052 , the p-value is 0.057, and the local Moran's I indicators are as listed in Table 3.

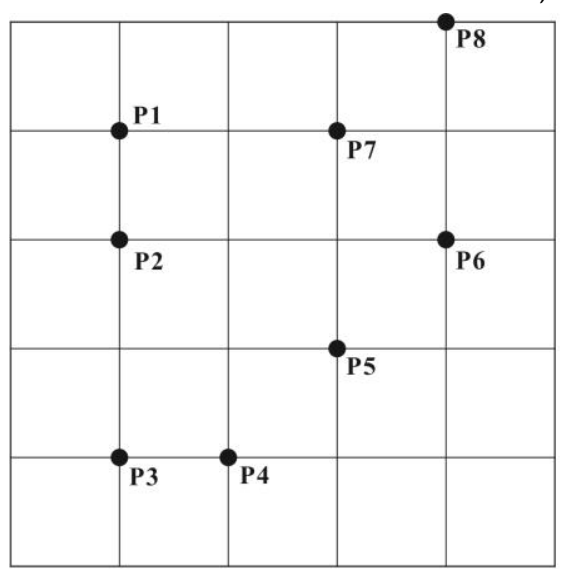

(a)

\begin{tabular}{|c|c|c|c|c|c|c|c|c|}
\hline & P1 & P2 & P3 & P4 & P5 & P6 & P7 & P8 \\
\hline P1 & 0 & 1 & 3 & $\sqrt{10}$ & $2 \sqrt{2}$ & $\sqrt{10}$ & 2 & $\sqrt{10}$ \\
\hline P2 & 1 & 0 & 2 & $\sqrt{5}$ & $\sqrt{5}$ & 3 & $\sqrt{5}$ & $\sqrt{13}$ \\
\hline P3 & 3 & 2 & 0 & 1 & $\sqrt{5}$ & $\sqrt{13}$ & $\sqrt{13}$ & 5 \\
\hline P4 & $\sqrt{10}$ & $\sqrt{5}$ & 1 & 0 & $\sqrt{2}$ & $2 \sqrt{2}$ & $\sqrt{10}$ & $2 \sqrt{5}$ \\
\hline P5 & $2 \sqrt{2}$ & $\sqrt{5}$ & $\sqrt{5}$ & $\sqrt{2}$ & 0 & $\sqrt{2}$ & 2 & $\sqrt{10}$ \\
\hline P6 & $\sqrt{10}$ & 3 & $\sqrt{13}$ & $2 \sqrt{2}$ & $\sqrt{2}$ & 0 & $\sqrt{2}$ & 2 \\
\hline P7 & 2 & $\sqrt{5}$ & $\sqrt{13}$ & $\sqrt{10}$ & 2 & $\sqrt{2}$ & 0 & $\sqrt{2}$ \\
\hline P8 & $\sqrt{10}$ & $\sqrt{13}$ & 5 & $2 \sqrt{5}$ & $\sqrt{10}$ & 2 & $\sqrt{2}$ & 0 \\
\hline
\end{tabular}

(b)

\begin{tabular}{|c|c|c|c|c|c|c|c|c|}
\hline & P1 & P2 & P3 & P4 & P5 & P6 & P7 & P8 \\
\hline P1 & 0 & 1 & 1 & 1 & 1 & 1 & 1 & 1 \\
\hline P2 & 1 & 0 & 1 & 1 & 1 & 1 & 1 & 1 \\
\hline P3 & 1 & 1 & 0 & 1 & 1 & 1 & 1 & 0 \\
\hline P4 & 1 & 1 & 1 & 0 & 1 & 1 & 1 & 0 \\
\hline P5 & 1 & 1 & 1 & 1 & 0 & 1 & 1 & 1 \\
\hline P6 & 1 & 1 & 1 & 1 & 1 & 0 & 1 & 1 \\
\hline P7 & 1 & 1 & 1 & 1 & 1 & 1 & 0 & 1 \\
\hline P8 & 1 & 1 & 0 & 0 & 1 & 1 & 1 & 0 \\
\hline
\end{tabular}

(c)

Figure 3. (a) Spatial distribution of points, (b) distance matrix between point pairs, and (c) spatially weighted matrix.

Table 3. Local Moran's I calculation results of the example in Figure 3.

\begin{tabular}{ccccccc}
\hline ID & X & Y & Value & Local Moran's I & Clustered Type & P-value \\
\hline P1 & 1 & 4 & 0.2 & -0.1758203 & Low-High & 0.001 \\
P2 & 1 & 3 & 0.4 & -0.0028961 & Low-High & 0.001 \\
P3 & 1 & 1 & 0.8 & -0.323655 & Insignificant & 0.382 \\
P4 & 2 & 1 & 0.5 & -0.0335362 & Insignificant & 0.134 \\
P5 & 3 & 2 & 0.1 & -0.1007592 & Low-High & 0.001 \\
P6 & 4 & 3 & 0.6 & 0.0541114 & High-High & 0.001 \\
P7 & 3 & 4 & 0.4 & -0.0111241 & Low-High & 0.001 \\
P8 & 4 & 5 & 0.3 & 0.2280927 & Low-Low & 0.001 \\
\hline
\end{tabular}




\subsubsection{Multivariate spatial cross-correlation}

Spatial cross-correlation indicates the extent to which the multiple attributes of a feature are cross-influenced by nearby features. The exploration of multivariate spatial crosscorrelation is a core functionality of current exploratory data analysis (EDA), knowledge discovery and data mining tools [61]. Anselin et al. (2002) proposed bivariate global (Eq. 3) and local (Eq. 4) Moran's I to quantify bivariate spatial cross-correlation [62]. They are calculated from

$$
\begin{aligned}
& I_{a b}=\frac{n \sum_{i}^{n} \sum_{j}^{n} w_{i j}\left(a_{i}-\bar{a}\right)\left(b_{j}-\bar{b}\right)}{\left(\sum_{i}^{n} \sum_{j}^{n} w_{i j}\right) \sum_{i}^{n}\left(a_{i}-\bar{a}\right)^{2}} \\
& I_{a b}(i)=\frac{n\left(a_{i}-\bar{a}\right)}{\sum_{i}^{n}\left(a_{i}-\bar{a}\right)^{2}} \sum_{j}^{n} w_{i j}\left(b_{j}-\bar{b}\right)
\end{aligned}
$$

where $a_{i}$ and $b_{j}$ are the observed values of variables $a$ and $b$ at positions $i$ and $j, n$ is the total number of observations, $\bar{a}$ and $\bar{b}$ are the mean values of the observations of variables $a$ and $b$, and $w_{i j}$ is the spatial weighted matrix.

Anselin (2019) proposed using the univariate local Geary's C to measure the squared distance in attribute space (i.e., along a line for the univariate case) between the values at a geographic location and its neighboring locations, which is summarized in the form of a weighted sum [13]. This indicator can be readily extended to a multivariate context. For example, consider two variables, $p$ and $q$. The squared distance $d_{i j}^{2}$ in two-dimensional attribute space between the values at observation $i$ and its geographic neighbor $j$ is:

$$
d_{i j}^{2}=\left(p_{i}-p_{j}\right)^{2}+\left(q_{i}-q_{j}\right)^{2}
$$

The bivariate local Geary's C can be defined as:

$$
\begin{aligned}
c_{a b}(i) & =\frac{1}{2} \sum_{j} w_{i j} d_{i j}^{2}=\frac{1}{2} \sum_{j} w_{i j}\left[\left(p_{i}-p_{j}\right)^{2}+\left(q_{i}-q_{j}\right)^{2}\right]=\frac{1}{2}\left[\sum_{j} w_{i j}\left(p_{i}-p_{j}\right)^{2}+\right. \\
\left.\sum_{j} w_{i j}\left(q_{i}-q_{j}\right)^{2}\right] & =\frac{1}{2}\left(c_{a}(\mathrm{i})+c_{b}(i)\right)
\end{aligned}
$$

where $p_{i}$ and $p_{j}$ are the observed values of variable $a$ at positions $i$ and $j, q_{i}$ and $q_{j}$ are the observed values of variable $b$ at positions $i$ and $j$, and $w_{i j}$ is the spatial weighted matrix.

Following standard practice in multivariate clustering analysis, these variables have been standardized such that the mean of the transformed variable is zero and its variance is one. Moreover, the concept of a local Geary' $\mathrm{C}$ is additive in the attribute dimension. Therefore, a multivariate local Geary's $C$ can be defined as:

$$
c_{\text {total }}(\mathrm{i})=\sum_{v=1}^{k} c_{v}(\mathrm{i}) / \mathrm{k}
$$

where $\mathrm{k}$ represents $\mathrm{k}$-dimensional attribute space, and $\mathrm{c}_{\mathrm{v}}(\mathrm{i})$ represents the univariate local Geary's C of variable $v$.

\subsection{Association rule mining and Apriori algorithm}

Association rule mining is used to reveal the association among items in a dataset. We assume that $\mathrm{D}=\left\{t_{1}, t_{2}, \ldots, t_{N}\right\}$ is the event dataset, $\mathrm{t}_{k}=\left\{i_{1}, i_{2}, \ldots, i_{K}\right\}$ represents an event corresponding to a geochemical sample, and $i_{k}$ represents an item belonging to an aggregated event $\mathrm{t}_{k}$. Itemset $\mathrm{I}=\left\{i_{1}, i_{2}, \ldots, i_{M}\right\}$ is a specific item combination, which contains $M$ different items. For a subset $\mathrm{X}$ in $\mathrm{I}$, if $\mathrm{X} \subseteq \mathrm{t}_{k}$, then the event $\mathrm{t}_{k}$ contains $\mathrm{X}$. The goal of association rule mining is to find an implicit form of $X \Rightarrow Y$, where $X \subseteq I, Y \subseteq I$, and $X \cap Y=\emptyset$. If the rule $X \Rightarrow Y$ exists, there are two key coefficients, the support degree $S$ and confidence $C$. The support degree $S(X \Rightarrow Y)=P(X \cup Y)$ represents the probability of co-occurrence of itemsets $X$ and $Y$. The confidence $C(X \Rightarrow Y)=P(Y \mid X)=P(X \cup Y) / P(X)$ represents conditional probability of occurrence of itemset $Y$ given that itemset $X$ has occurred. The itemsets which satisfy the minimum threshold $\left(S_{\min }\right)$ of support degree are socalled frequent itemsets, and those which satisfy both $S_{\min }$ and a minimum threshold of confidence $\left(\mathrm{C}_{\mathrm{min}}\right)$ are strong association rules. 
The Apriori algorithm [57] can be decomposed into two main steps. The basic intuition is that any subset of a frequent itemset must be frequent. The first step is to generate frequent itemsets, as shown in Figure 4. The second step is to extract strong association rules based on frequent itemsets, as shown in Figure 5. The Apriori algorithm generates the candidate itemsets to be counted in a pass by using only the frequent itemsets in the previous pass. To improve the efficiency of frequent itemset extraction, the method utilizes a pruning strategy in order to compress the search space, that is, all non-empty subsets of frequent item-sets must also be frequent, and all parent sets of nonfrequent itemsets are nonfrequent.

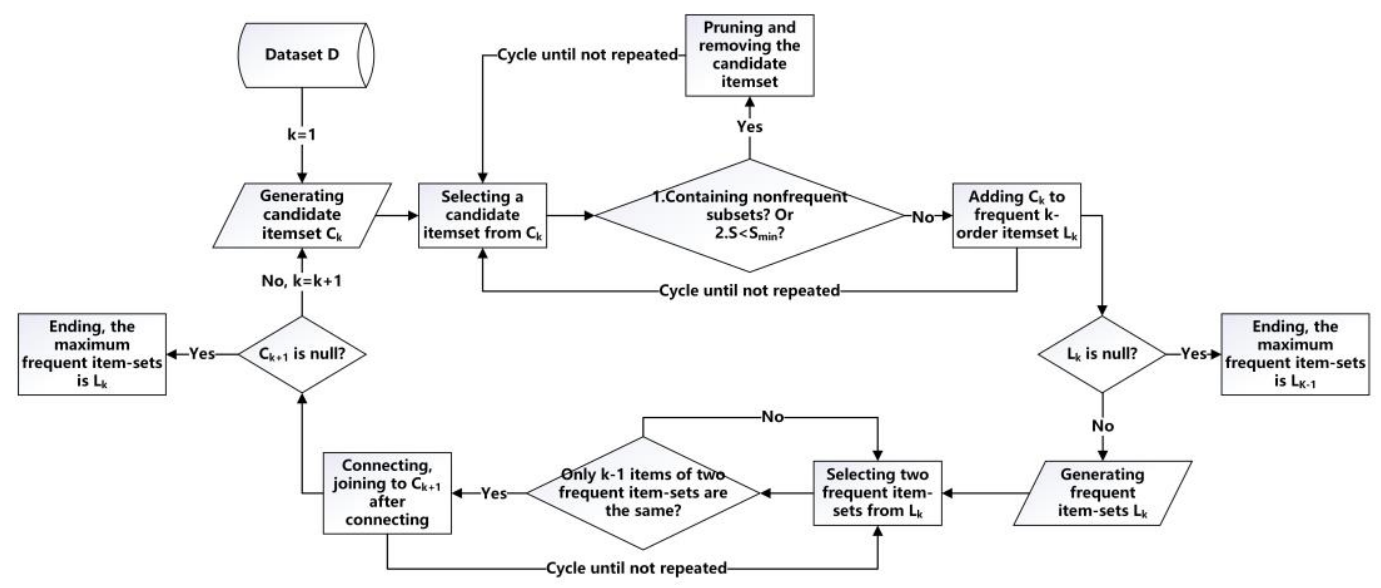

Figure 4. Algorithm for generating frequent itemsets.

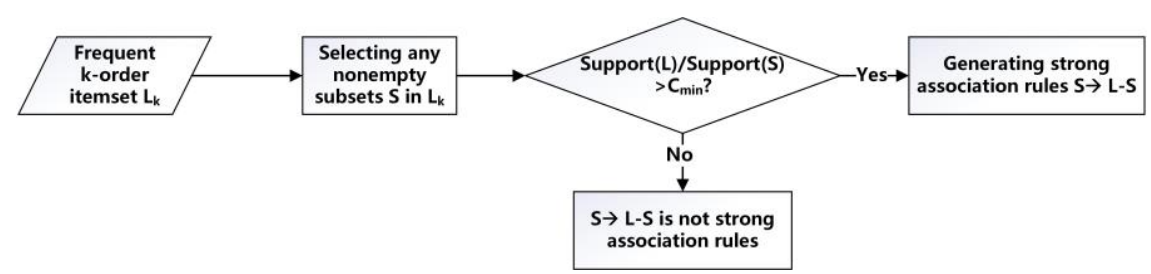

Figure 5. Algorithm for extracting strong association rules based on frequent itemsets.

\section{Results and discussion}

\subsection{Spatial auto-correlation of elements}

\subsubsection{Univariate spatial auto-correlation of individual elements}

We calculated the spatial auto-correlation and cross-correlation indicators of each element using open-source software packages Geoda (http://geodacenter.github.io) and spdep (https://github.com/r-spatial/spdep). Then, we applied the Z-score to test the significance of spatial auto-correlation and cross-correlation statistics. Because the global Moran's I can be tested by normal or permutation tests [8], and the Z-score was calculated by Monte Carlo simulation by randomly sampling 999 permutations. The global Moran's I, global Geary's C, and global Getis-Ord's G for 15 elements passed the statistical significance test and are consistent with each other (Table 4). The global Moran's I and Geary's $\mathrm{C}$ are both suitable for characterizing the overall spatial pattern of an element, however, the global Getis-Ord's G only indicates whether an element's concentration exhibits a positive correlation (LL clustered or HH clustered) or is randomly distributed. It can't be used to ascertain a negative correlation or compare the correlation between elements.

Table 4. Univariate global spatial auto-correlation indicators for 15 elements in the study area.

Variable Global Moran's I Global Geary's C Global Getis-Ord's G




\begin{tabular}{cccccccc} 
& I & P-value & C & P-value & G & P-value & E(G) \\
\hline $\log 10(\mathrm{Au})$ & 0.059 & $<2.2 \mathrm{e}-16$ & 0.949 & $<2.2 \mathrm{e}-16$ & 0.009 & $<2.2 \mathrm{e}-16$ & $5.1 \mathrm{e}-09$ \\
$\log 10(\mathrm{Sn})$ & 0.439 & $<2.2 \mathrm{e}-16$ & 0.563 & $<2.2 \mathrm{e}-16$ & 0.014 & $<2.2 \mathrm{e}-16$ & $6.7 \mathrm{e}-09$ \\
$\log 10(\mathrm{Ag})$ & 0.430 & $<2.2 \mathrm{e}-16$ & 0.570 & $<2.2 \mathrm{e}-16$ & 0.013 & $<2.2 \mathrm{e}-16$ & $9.0 \mathrm{e}-09$ \\
$\log 10(\mathrm{As})$ & 0.451 & $<2.2 \mathrm{e}-16$ & 0.551 & $<2.2 \mathrm{e}-16$ & 0.012 & $<2.2 \mathrm{e}-16$ & $1.1 \mathrm{e}-08$ \\
$\log 10(\mathrm{Sb})$ & 0.608 & $<2.2 \mathrm{e}-16$ & 0.394 & $<2.2 \mathrm{e}-16$ & 0.014 & $<2.2 \mathrm{e}-16$ & $1.3 \mathrm{e}-08$ \\
$\log 10(\mathrm{Bi})$ & 0.438 & $<2.2 \mathrm{e}-16$ & 0.564 & $<2.2 \mathrm{e}-16$ & 0.019 & $<2.2 \mathrm{e}-16$ & $5.2 \mathrm{e}-08$ \\
$\log 10(\mathrm{Co})$ & 0.423 & $<2.2 \mathrm{e}-16$ & 0.578 & $<2.2 \mathrm{e}-16$ & 0.009 & $<2.2 \mathrm{e}-16$ & $5.8 \mathrm{e}-10$ \\
$\log 10(\mathrm{Cu})$ & 0.468 & $<2.2 \mathrm{e}-16$ & 0.535 & $<2.2 \mathrm{e}-16$ & 0.012 & $<2.2 \mathrm{e}-16$ & $5.3 \mathrm{e}-09$ \\
$\log 10(\mathrm{La})$ & 0.259 & $<2.2 \mathrm{e}-16$ & 0.740 & $<2.2 \mathrm{e}-16$ & 0.009 & $<2.2 \mathrm{e}-16$ & $9.1 \mathrm{e}-10$ \\
$\log 10(\mathrm{~Pb})$ & 0.500 & $<2.2 \mathrm{e}-16$ & 0.500 & $<2.2 \mathrm{e}-16$ & 0.011 & $<2.2 \mathrm{e}-16$ & $5.1 \mathrm{e}-09$ \\
$\log 10(\mathrm{Zn})$ & 0.530 & $<2.2 \mathrm{e}-16$ & 0.468 & $<2.2 \mathrm{e}-16$ & 0.010 & $<2.2 \mathrm{e}-16$ & $1.1 \mathrm{e}-09$ \\
$\log 10(\mathrm{~W})$ & 0.365 & $<2.2 \mathrm{e}-16$ & 0.638 & $<2.2 \mathrm{e}-16$ & 0.015 & $<2.2 \mathrm{e}-16$ & $2.4 \mathrm{e}-08$ \\
$\log 10(\mathrm{Mo})$ & 0.430 & $<2.2 \mathrm{e}-16$ & 0.572 & $<2.2 \mathrm{e}-16$ & 0.012 & $<2.2 \mathrm{e}-16$ & $4.0 \mathrm{e}-09$ \\
$\log 10(\mathrm{Nb})$ & 0.181 & $<2.2 \mathrm{e}-16$ & 0.817 & $<2.2 \mathrm{e}-16$ & 0.009 & $<2.2 \mathrm{e}-16$ & $8.2 \mathrm{e}-10$ \\
$\log 10(\mathrm{Cd})$ & 0.459 & $<2.2 \mathrm{e}-16$ & 0.539 & $<2.2 \mathrm{e}-16$ & 0.012 & $<2.2 \mathrm{e}-16$ & $4.0 \mathrm{e}-09$ \\
\hline $\mathrm{P}$ &
\end{tabular}

P-value $<0.05$ means that the indicator passes the statistical significance test.

The global Getis-Ord's G shows that all the 15 elements have a positive correlation in the study area. The global Moran's I and Geary's C show that Au is randomly distributed, and the other 14 elements are positively correlated. The elements ordered from high to low correlation are $\mathrm{Sb}, \mathrm{Zn}, \mathrm{Pb}, \mathrm{Cu}, \mathrm{Cd}, \mathrm{As}, \mathrm{Sn}, \mathrm{Bi}, \mathrm{Ag}, \mathrm{Mo}, \mathrm{Co}, \mathrm{W}$, La and $\mathrm{Nb}$ (Table 4). Except for Au, the global Moran's I and Geary's C are consistent with Getis-Ord's G. According to the geological survey report, an Au deposit was found in the study area [59]. However, because of the low concentrations of $\mathrm{Au}$ in most sampling points of the study area, it would be easy to overlook the local clustering in the global spatial auto-correlation analysis.

We calculated the local Moran's I of major elements in the study area and visualized the results via a Voronoi diagram (Figure 6). Anselin (1995) proposed a local indicator of spatial association (LISA) statistic that satisfies the following two requirements: a. the LISA for each observation gives an indication of the extent of significant spatial clustering of similar values around that observation; $b$. the sum of LISAs for all observations is proportional to a global indicator of spatial association [11]. By calculating the local Moran's I $I(i)$ in each quadrant, this divides the concentrations of elements into 5 categories: insignificant or high-high (HH), low-low (LL), low-high (LH), or high-low (HL) clustering [11]. A local Moran's I clustering map (LMIC) represents different types of association between the value at a given location and its spatial lag, i.e., the weighted average of the values in the surrounding locations. The LISA significance map is shown in Figure 7, in which we set $\mathrm{P}=0.05$. The local Moran's I clustering map is shown in Figure 8 . These results are consistent with the Moran's I clustering results, which show that the HH and LL clustering in LMIC can reflect the spatial pattern of elements' concentrations with a certain statistical significance. In addition, maps of local Moran's I have natural transitions from strong to weak, which capture the local details and are consistent with the distributions of elements in nature.

Moreover, we also calculated indicators of the local Geary's C and the local GetisOrd's G of all the elements in the study area. The HH and LL clustered values of the local Moran's I and the local Geary's C are similar; however, the local Getis-Ord's G covers a broader space, especially $\mathrm{Sb}, \mathrm{As}, \mathrm{Cu}$ and $\mathrm{Co}$. Compared with local Geary's $\mathrm{C}$ and local Getis-Ord's G, we can identify points with HH, LL, LH, and HL clustering with a precise 
meaning for each category from the local Moran's I. Therefore, we chose the LMIC results to mine the association rules of various elements.

(a)
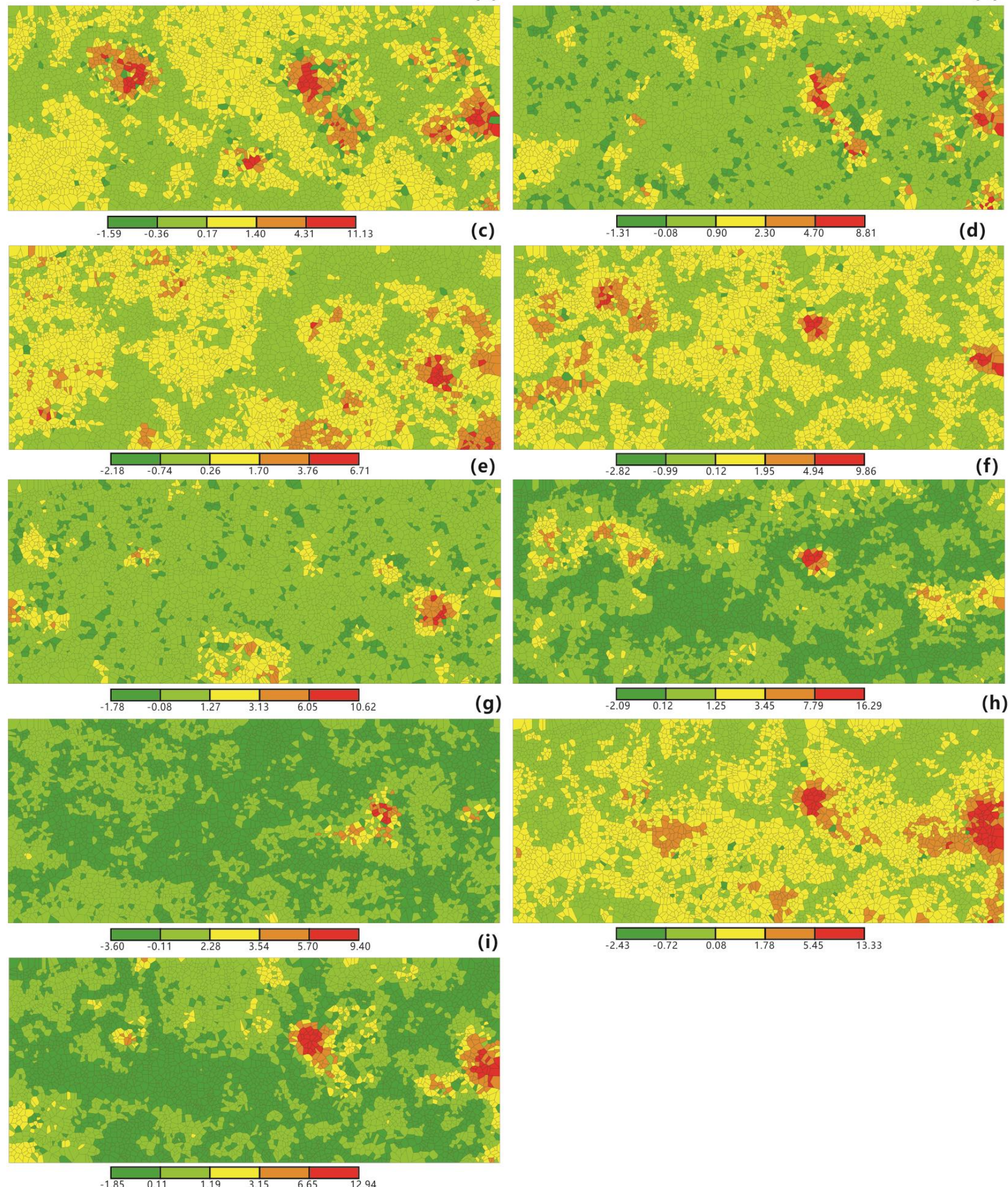

Figure 6. Voronoi diagrams of local Moran's I indicators for major elements: (a) Ag, (b) As, (c) Sb, (d) Bi, (e) Co, (f) Cu, (g) La, (h) Zn, and (i) $\mathrm{Cd}$. 
(a)

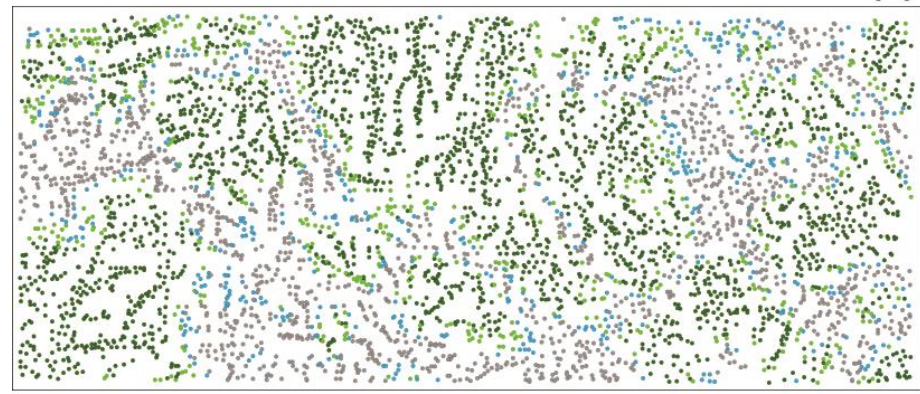

(c)

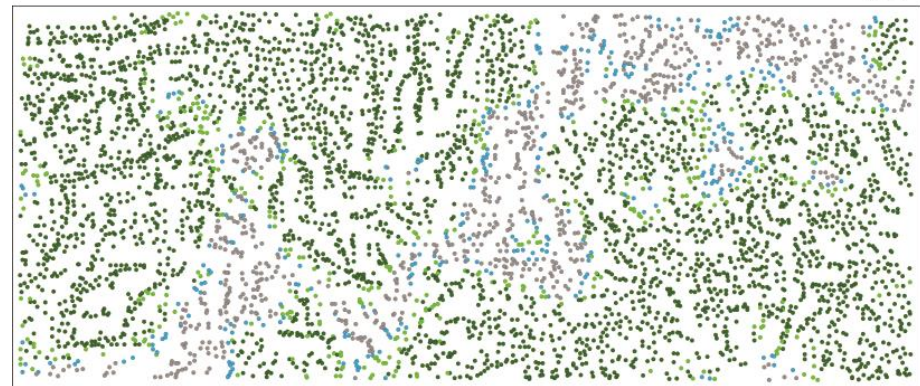

(e)

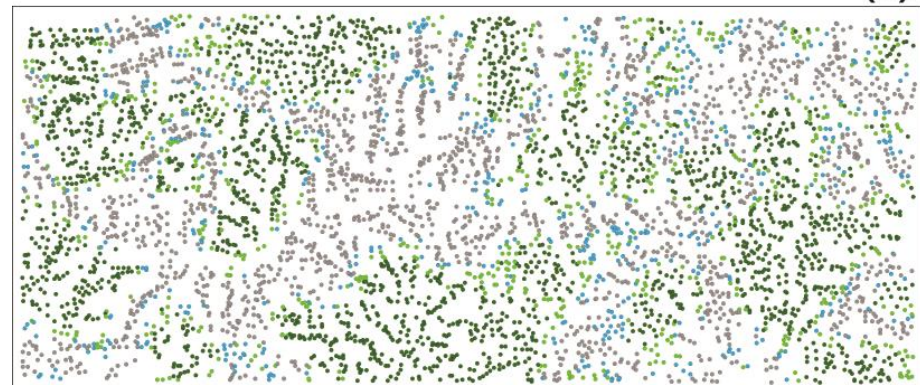

(g)

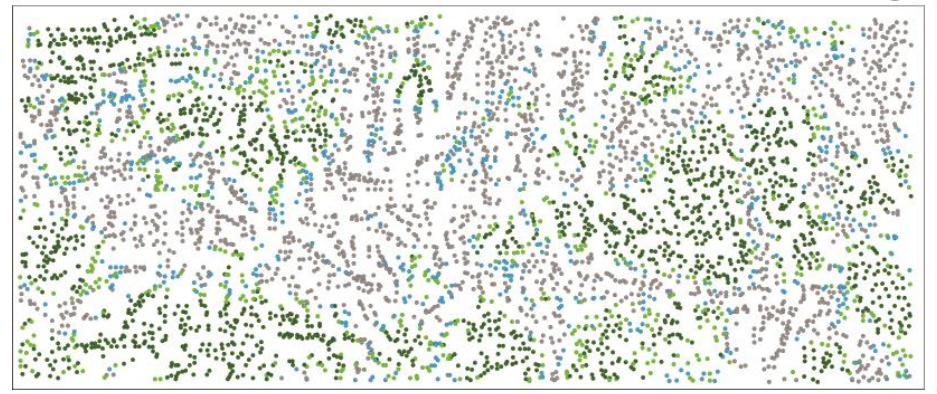

(i)

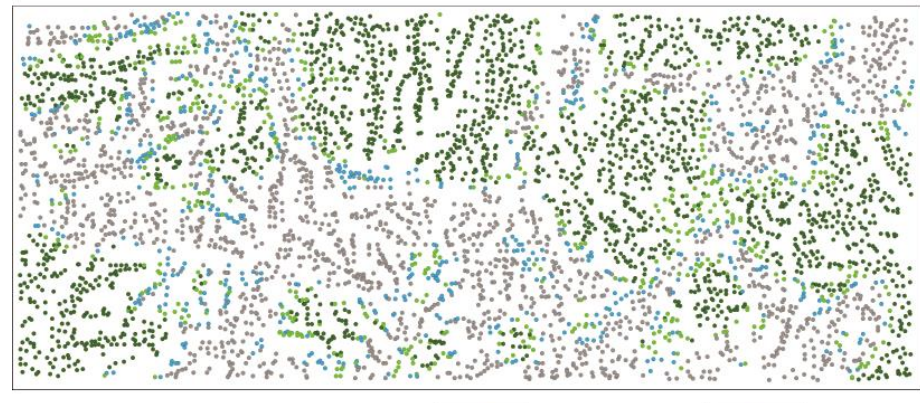

$\mathrm{P}=0.001 \square \mathrm{P}=0.01$ (b)

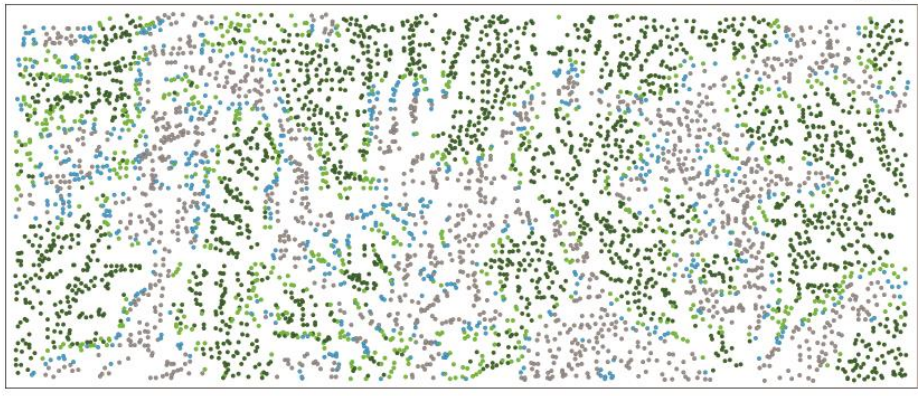

(d)

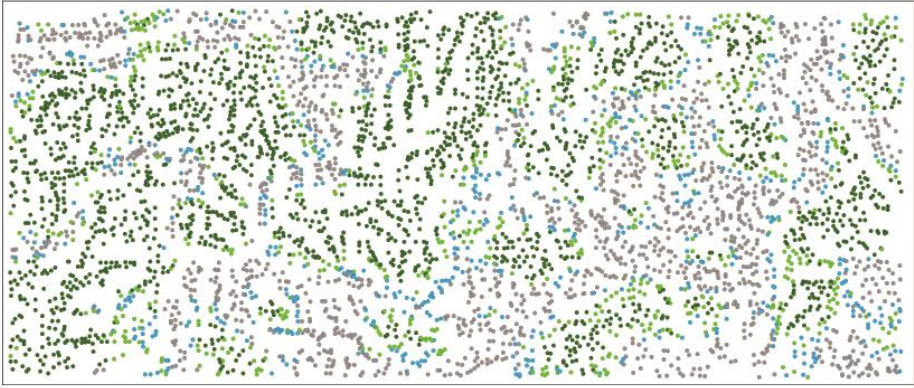

(f)

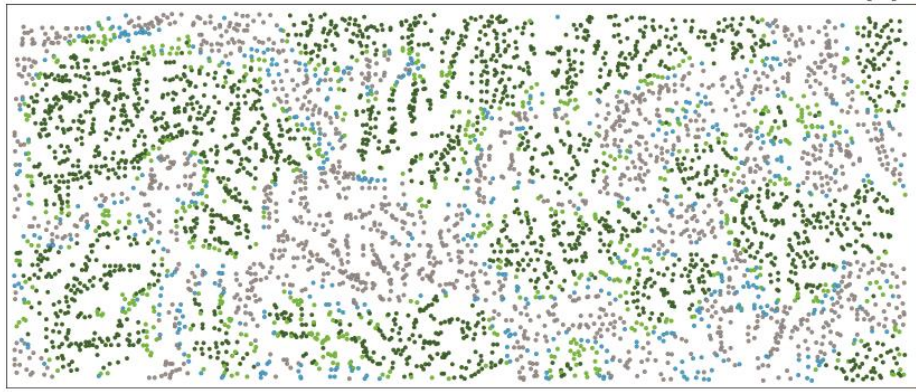

)

(h)

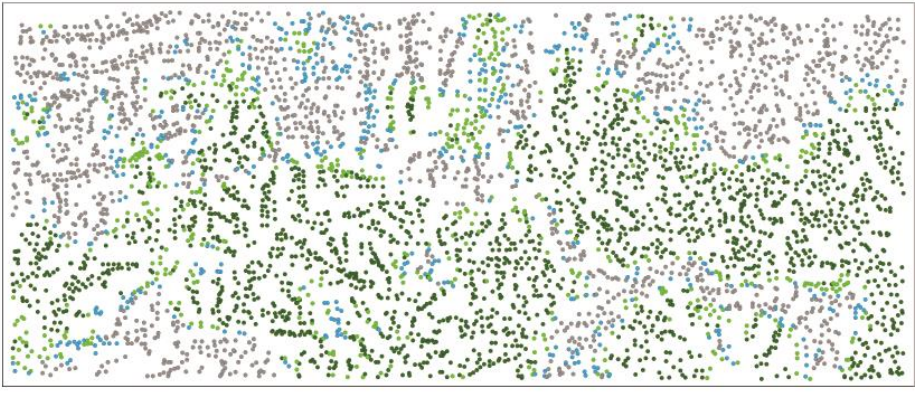

(i) 
(a)

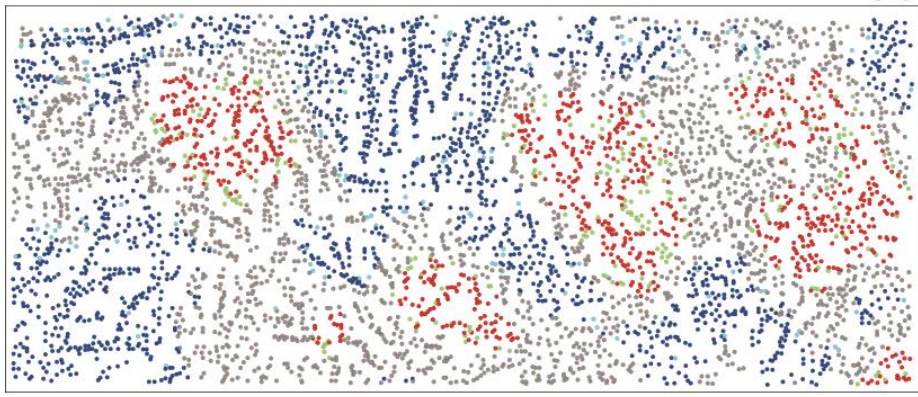

(c)

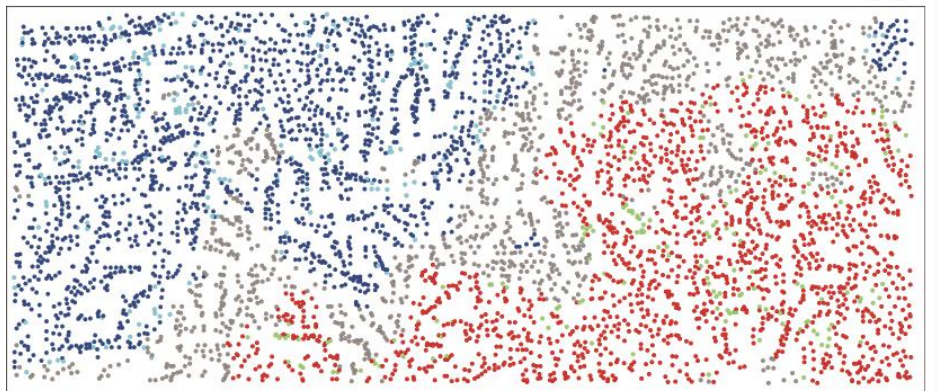

(e)

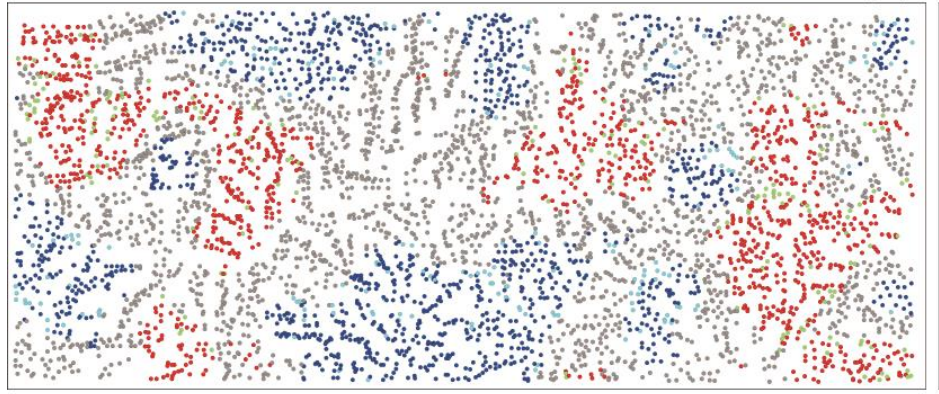

(g)

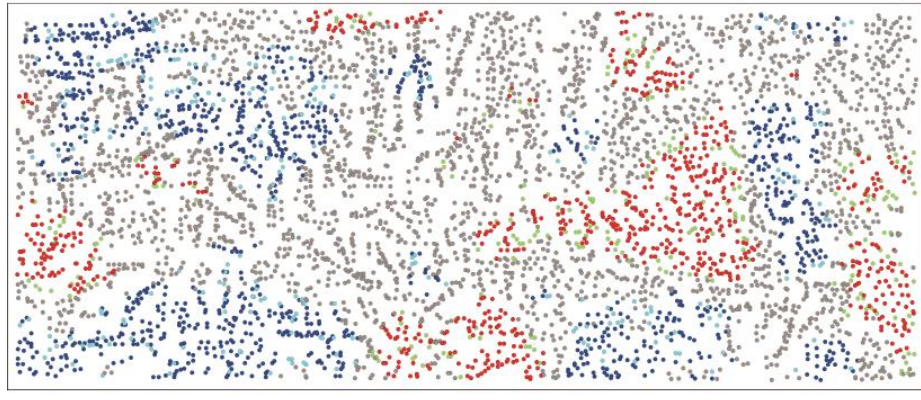

(i)

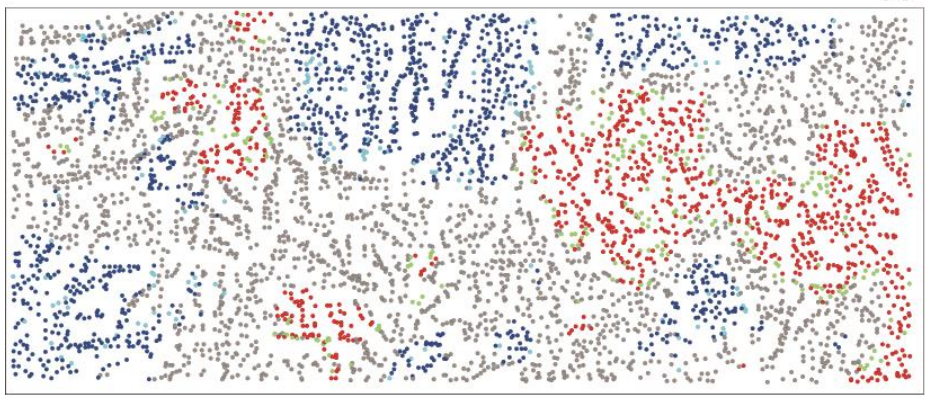

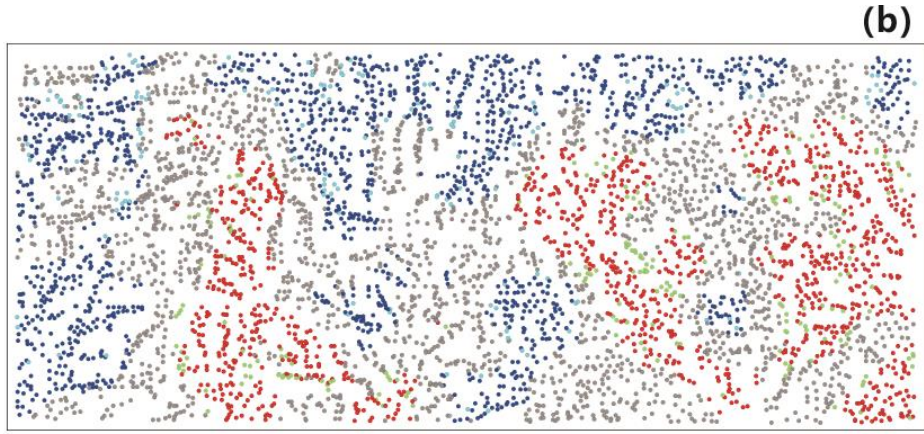

(d)
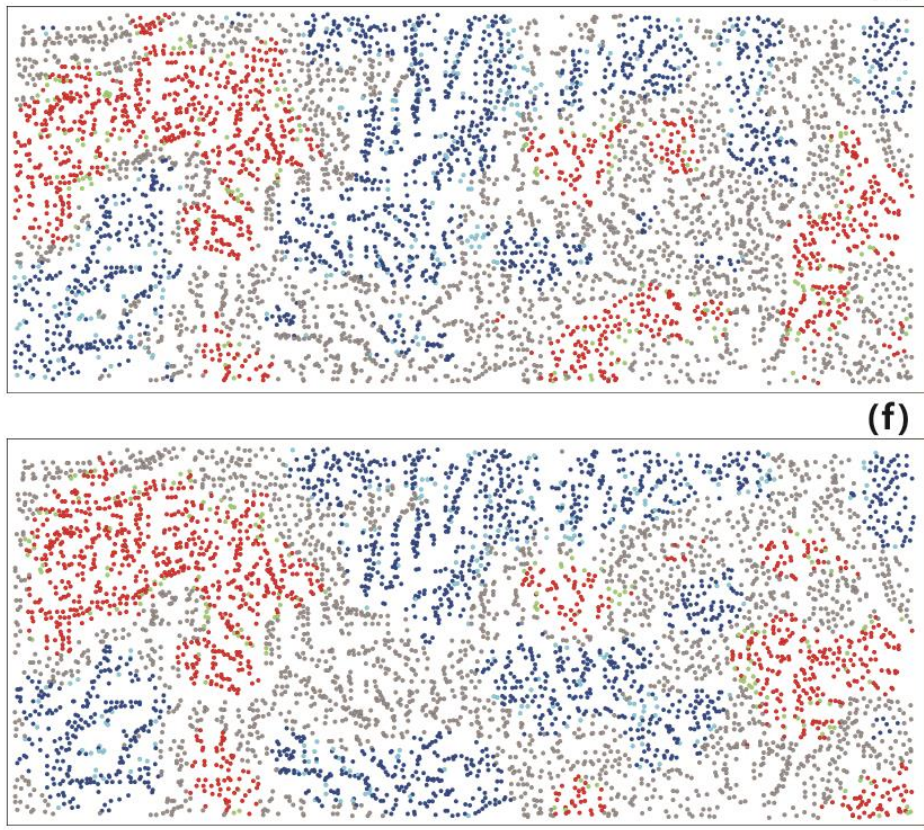

(f)

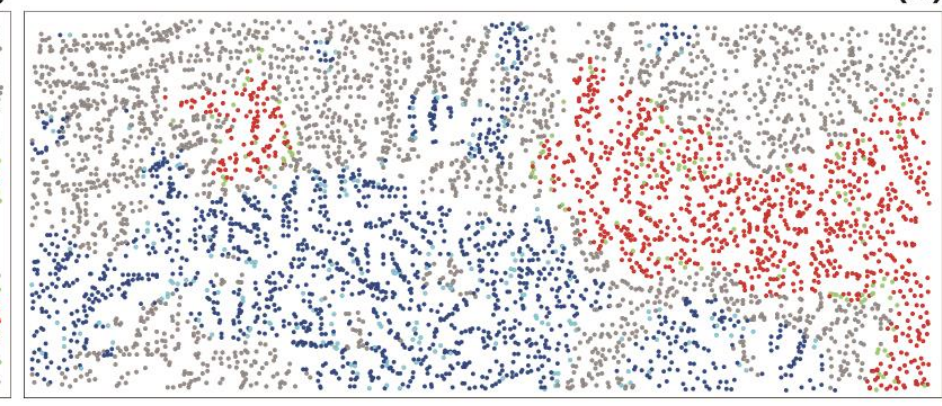

(h)

- $\mathrm{HH} \bigcirc \mathrm{OL} \bigcirc \mathrm{OHH} \bigcirc \mathrm{HL} \square$ Insignificant

Figure 8. Clustering map of local Moran's I indicators for major elements: (a) Ag, (b) As, (c) Sb, (d) Bi, (e) Co, (f) Cu, (g) La, (h) Zn, and (i) Cd.

4.1.2. Bivariate spatial cross-correlation between two elements 
The bivariate global Moran's I for 15 elements in the study area are shown in Table 5 , and all the calculated results passed the statistical significance test. The diagonal elements in Table 5 are consistent with the univariate global Moran's I. The elements with strong positive correlations include $\mathrm{Pb}$ and $\mathrm{Cd}, \mathrm{Pb}$ and $\mathrm{Zn}, \mathrm{Cu}$ and $\mathrm{Bi}$, and $\mathrm{Zn}$ and $\mathrm{Cd}$, and those with negative correlations include $\mathrm{La}$ and $\mathrm{Co}$, and $\mathrm{La}$ and $\mathrm{Cu}$ (Tables 6 and 7).

Table 5. Bivariate global Moran's I for 15 elements in the study area.

\begin{tabular}{ccccccccccccccccccc}
\hline $\begin{array}{c}\text { Element/ } \\
\text { log10() }\end{array}$ & $\mathbf{A u}$ & $\mathbf{S n}$ & $\mathbf{A g}$ & $\mathbf{A s}$ & $\mathbf{S b}$ & $\mathbf{B i}$ & $\mathbf{C o}$ & $\mathbf{C u}$ & $\mathbf{L a}$ & $\mathbf{P b}$ & $\mathbf{Z n}$ & $\mathbf{W}$ & $\mathbf{M o}$ & $\mathbf{N b}$ & $\mathbf{C d}$ \\
\hline $\mathrm{Au}$ & 0.06 & 0.03 & 0.03 & 0.03 & 0.03 & 0.01 & -0.03 & 0.00 & 0.01 & 0.02 & -0.02 & 0.01 & -0.02 & -0.01 & 0.02 \\
$\mathrm{Sn}$ & 0.03 & 0.44 & 0.28 & 0.27 & 0.20 & 0.30 & 0.15 & 0.29 & -0.03 & 0.29 & 0.15 & 0.19 & 0.08 & -0.03 & 0.30 \\
$\mathrm{Ag}$ & 0.03 & 0.28 & 0.43 & 0.31 & 0.26 & 0.25 & 0.15 & 0.26 & 0.01 & 0.36 & 0.30 & 0.22 & 0.14 & 0.02 & 0.34 \\
$\mathrm{As}$ & 0.03 & 0.27 & 0.31 & 0.45 & 0.35 & 0.22 & 0.19 & 0.22 & -0.02 & 0.34 & 0.26 & 0.16 & 0.09 & 0.02 & 0.33 \\
$\mathrm{Sb}$ & 0.03 & 0.20 & 0.26 & 0.35 & 0.61 & 0.15 & 0.11 & 0.10 & 0.04 & 0.32 & 0.26 & 0.12 & -0.01 & 0.00 & 0.30 \\
$\mathrm{Bi}$ & 0.01 & 0.30 & 0.25 & 0.22 & 0.15 & 0.44 & 0.18 & 0.36 & -0.06 & 0.28 & 0.21 & 0.27 & 0.23 & 0.03 & 0.24 \\
$\mathrm{Co}$ & -0.03 & 0.15 & 0.15 & 0.19 & 0.11 & 0.18 & 0.42 & 0.31 & -0.15 & 0.20 & 0.22 & 0.15 & 0.15 & 0.01 & 0.16 \\
$\mathrm{Cu}$ & 0.00 & 0.29 & 0.26 & 0.22 & 0.10 & 0.36 & 0.31 & 0.47 & -0.13 & 0.26 & 0.22 & 0.29 & 0.27 & 0.04 & 0.23 \\
$\mathrm{La}$ & 0.01 & -0.03 & 0.01 & -0.02 & 0.04 & -0.06 & -0.15 & -0.13 & 0.26 & 0.06 & 0.06 & -0.02 & -0.01 & 0.07 & 0.04 \\
$\mathrm{~Pb}$ & 0.02 & 0.29 & 0.36 & 0.34 & 0.32 & 0.28 & 0.20 & 0.26 & 0.06 & 0.50 & 0.42 & 0.23 & 0.16 & 0.05 & 0.43 \\
$\mathrm{Zn}$ & -0.02 & 0.15 & 0.30 & 0.26 & 0.26 & 0.21 & 0.22 & 0.22 & 0.06 & 0.42 & 0.53 & 0.22 & 0.21 & 0.22 & 0.36 \\
$\mathrm{~W}$ & 0.01 & 0.19 & 0.22 & 0.16 & 0.12 & 0.27 & 0.15 & 0.29 & -0.02 & 0.23 & 0.22 & 0.37 & 0.32 & 0.07 & 0.19 \\
$\mathrm{Mo}$ & -0.02 & 0.08 & 0.14 & 0.09 & -0.01 & 0.23 & 0.15 & 0.27 & -0.01 & 0.16 & 0.21 & 0.32 & 0.43 & 0.10 & 0.11 \\
$\mathrm{Nb}$ & -0.01 & -0.03 & 0.02 & 0.02 & 0.00 & 0.03 & 0.01 & 0.04 & 0.07 & 0.05 & 0.22 & 0.07 & 0.10 & 0.18 & 0.03 \\
$\mathrm{Cd}$ & 0.02 & 0.30 & 0.34 & 0.33 & 0.30 & 0.24 & 0.16 & 0.23 & 0.04 & 0.43 & 0.36 & 0.19 & 0.11 & 0.03 & 0.46 \\
\hline
\end{tabular}

Table 6. Bivariate global Moran's I for elements with positive correlations.

\begin{tabular}{cc}
\hline \multicolumn{1}{c}{$\boldsymbol{I}_{\boldsymbol{a b}}$} & Positive correlation \\
\hline$I_{a b}=0.43$ & $\mathrm{~Pb}-\mathrm{Cd}$ \\
$I_{a b}=0.42$ & $\mathrm{~Pb}-\mathrm{Zn}$ \\
$I_{a b}=0.36$ & $\mathrm{Ag}-\mathrm{Pb} 、 \mathrm{Cu}-\mathrm{Bi} 、 \mathrm{Zn}-\mathrm{Cd}$ \\
$I_{a b}=0.35$ & $\mathrm{As}-\mathrm{Sb}$ \\
$I_{a b}=0.34$ & $\mathrm{Ag}-\mathrm{Cd} 、 \mathrm{~Pb}-\mathrm{As}$ \\
$I_{a b}=0.33$ & $\mathrm{As}-\mathrm{Cd}$ \\
$I_{a b}=0.32$ & $\mathrm{~Pb}-\mathrm{Sb} 、 \mathrm{Mo}-\mathrm{W}$ \\
$I_{a b}=0.31$ & $\mathrm{Ag}-\mathrm{As} 、 \mathrm{Cu}-\mathrm{Co}$ \\
$I_{a b}=0.30$ & $\mathrm{Sn}-\mathrm{Bi} 、 \mathrm{Sn}-\mathrm{Cd} 、 \mathrm{Ag}-\mathrm{Zn} 、 \mathrm{Sb}-\mathrm{Cd}$ \\
\hline
\end{tabular}

Table 7. Bivariate global Moran's I for elements with negative correlations. 


\begin{tabular}{cc}
\hline $\boldsymbol{I}_{\boldsymbol{a b}}$ & Negative correlation \\
\hline$I_{a b}=-0.13$ & La-Co \\
$I_{a b}=-0.15$ & La-Cu \\
\hline
\end{tabular}

The clustering map of bivariate local Moran's I divides the sampling points into 5 categories, i.e., insignificant, high-high (HH), low-low (LL), low-high (LH), and high-low (HL) clustered. However, their meanings are different from categories in a univariate clustering map. In the clustering map of bivariate local Moran's I, $I_{a b}(i)$ indicates the spatial pattern of the related element $b$ around the main element $a$. From this, we plotted $I_{\mathrm{CuCo}}$ $I_{\mathrm{CoCu}}, I_{\mathrm{CuBi}}$ and $I_{\mathrm{AsSb}}$, as shown in Figure 9. In the $I_{\mathrm{CuCo}}$ and $I_{\mathrm{CoCu}}$, the sampling points with high-high $(\mathrm{HH})$ and low-low (LL) clustering are consistent with the univariate $I_{\mathrm{Cu}}$ and $I_{\mathrm{Co}}$. Therefore, $I_{\mathrm{CuCo}}$ and $I_{\mathrm{CoCu}}$ show that the spatial distributions of $\mathrm{Cu}$ and Co in the study area are similar and positively cross-correlated. Due to the differences in the spatial distribution of $\mathrm{Cu}$ and $\mathrm{Co}$, there are some differences in $I_{\mathrm{CuCo}}$ and $I_{\mathrm{CoCu}}$ after exchanging the main variable and related variable. The high-high $(\mathrm{HH})$ clustering in $I_{\mathrm{CuBi}}$ and $I_{\mathrm{AsSb}}$ also has obvious regionality. The map for $I_{\mathrm{LaCu}}$ and $I_{\mathrm{LaCo}}$ is shown in Figure 10. There are apparent areas of low-high (LH) and high-low (HL) clustering in Figure 10, which indicate a negative cross-correlation of the two elements. Therefore, the bivariate local Moran's I effectively reveals whether two elements have a spatial cross-correlation. 
(a)

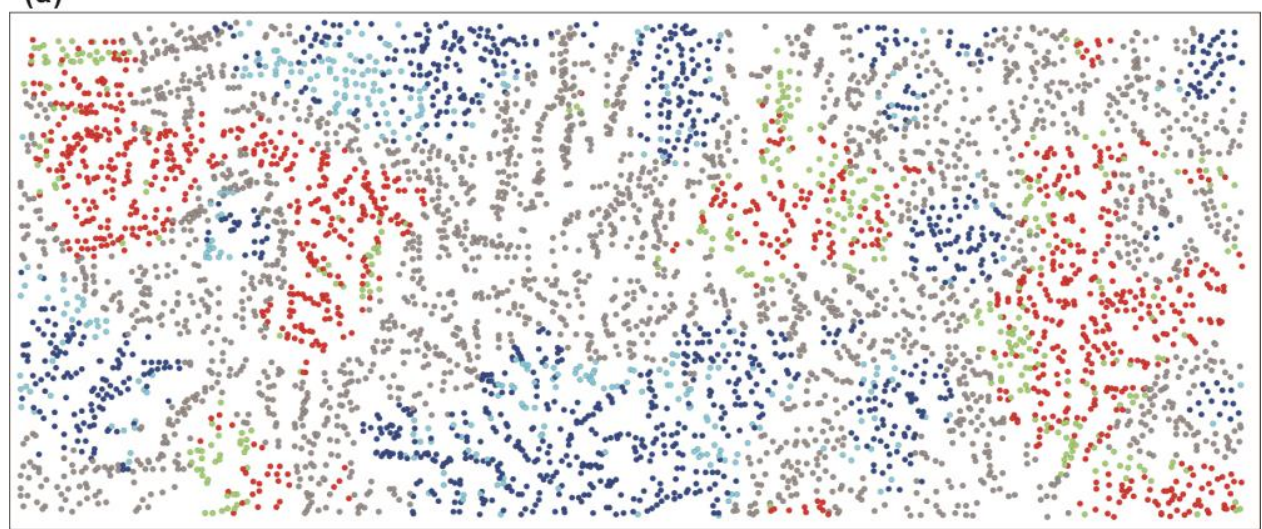

(b)

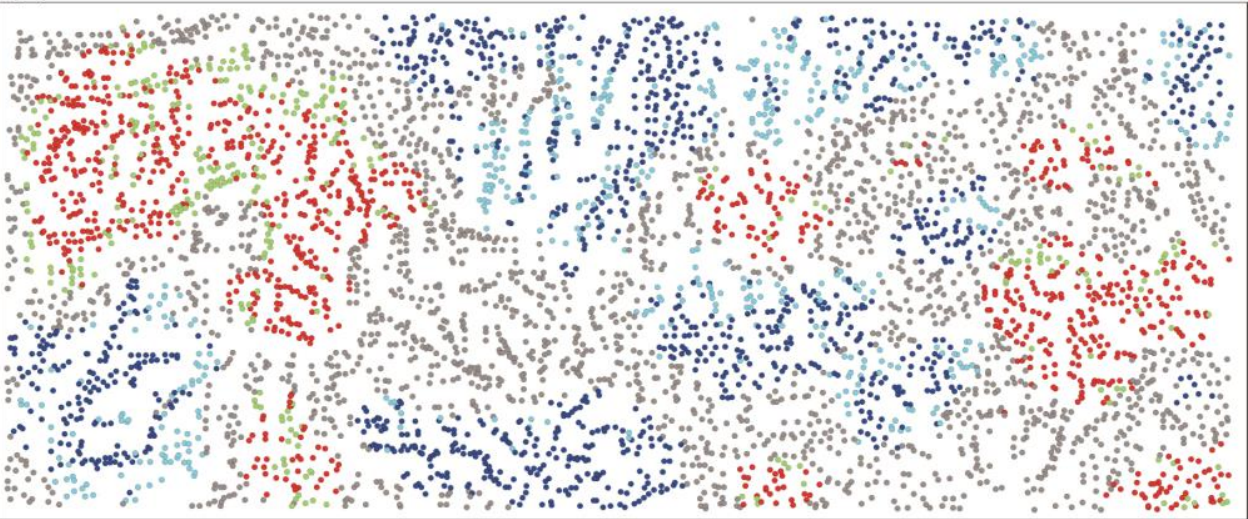

(c)

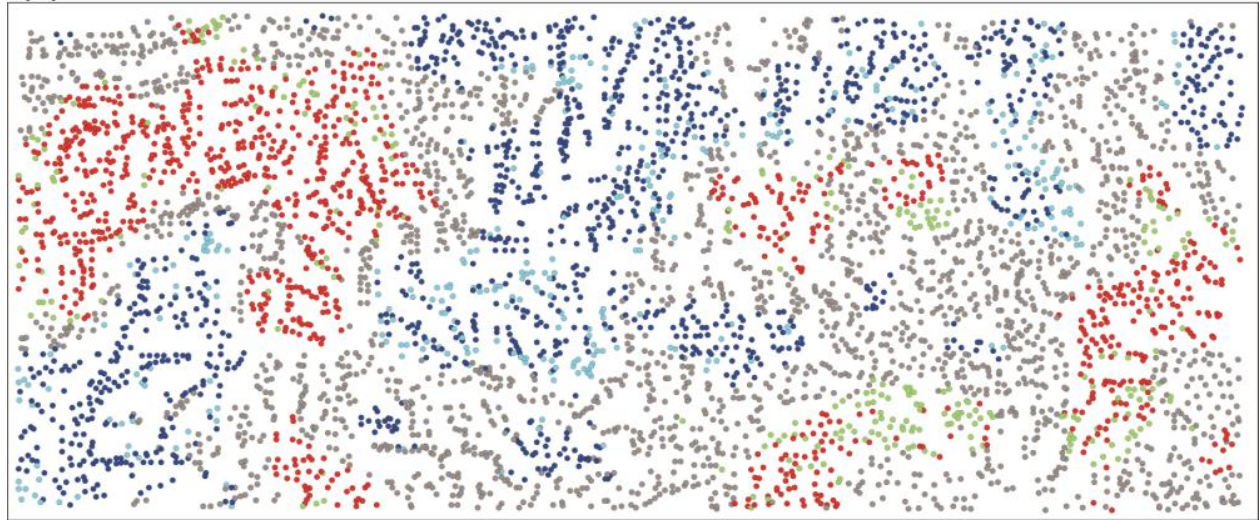

(d)

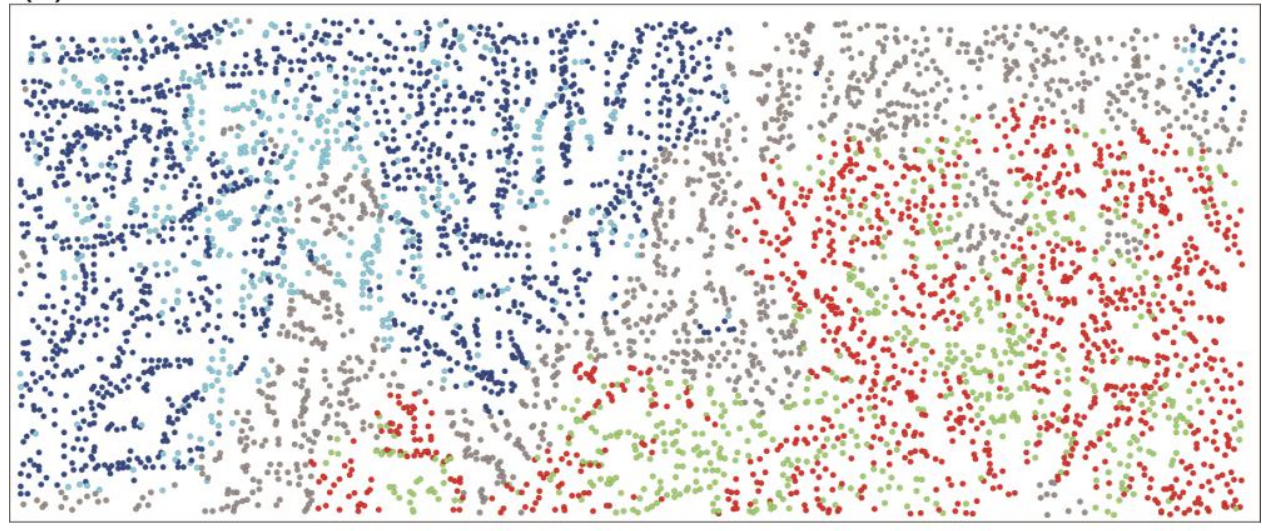

$\bullet \mathrm{HH} \square \mathrm{LL} \square \mathrm{LH} \square \mathrm{LL} \square$ Insignificant

Figure 9. Clustering map of bivariate local Moran's I with mainly positive cross-correlation: (a) $I_{\mathrm{CuCo}},(\mathrm{b}) I_{\mathrm{CoCu}}$, (c) $I_{\mathrm{CuBi}}$, and (d) $I_{\mathrm{AsSb}}$. 
(a)

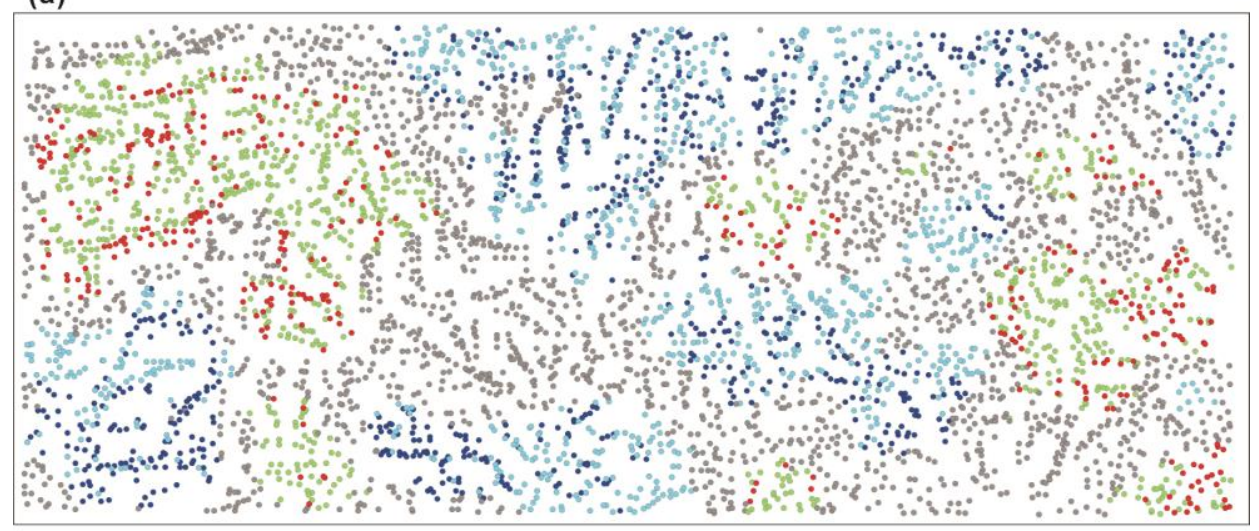

(b)

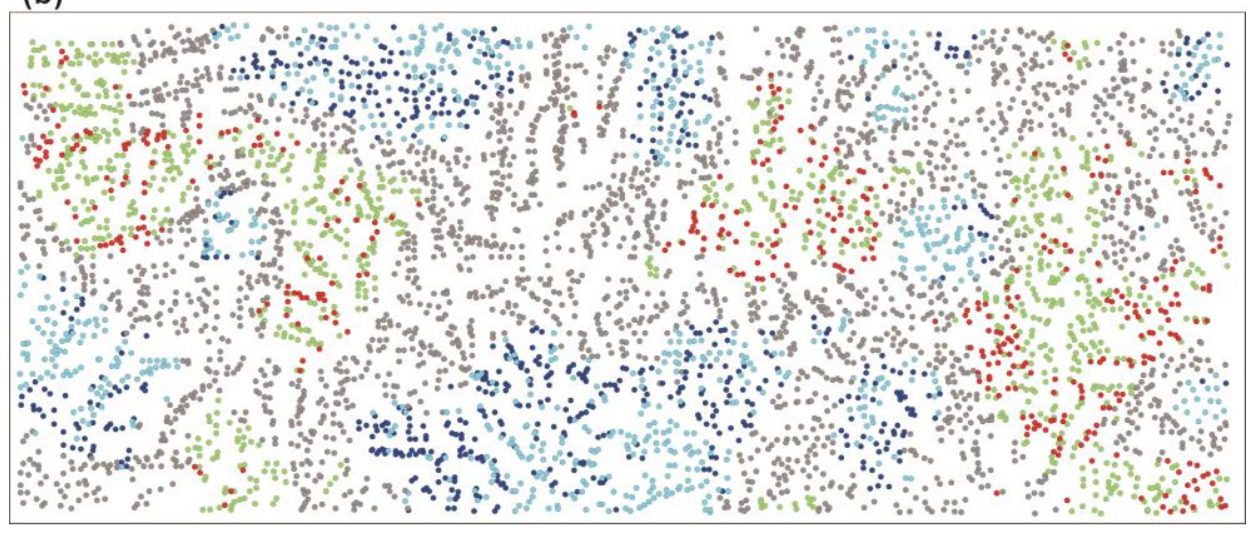

\section{$\square \mathrm{HH} \square \mathrm{LL} \square \mathrm{LH} \square \mathrm{LL} \square$ Insignificant}

Figure 10. Clustering map of bivariate local Moran's I with mainly negative cross-correlation: (a) $I_{\mathrm{LaCu}}$ and (b) $I_{\mathrm{LaCo}}$.

\subsection{Association rules among multiple elements}

\subsubsection{Association rule mining}

The 4959 geochemical sampling points were each taken as an event in the Apriori algorithm. Then we reorganized the geochemical concentration data into the original dataset D for association rule mining according to clustering by local univariate Moran's I, as shown in Table 8. Table 9 shows the statistics for the LMIC analysis. Some items frequently appear in events, while some items are very sparse. If the support threshold in the Apriori algorithm is set too small, the efficiency of the mining algorithm is low, and a large number of meaningless rules may be extracted. If the support threshold is set too large, the efficiency of the mining algorithm is high, but it may filter out some sparse items. For this study, we took the support threshold $S_{\min }=0.05$ and confidence threshold $\mathrm{C}_{\min }=0.7$.

Table 8. Original example dataset for association rule mining.

\begin{tabular}{|c|c|c|c|c|c|c|c|c|c|c|c|c|c|c|c|}
\hline $\begin{array}{c}t_{k} \\
\text { (Point) }\end{array}$ & $\begin{array}{c}i_{1} \\
(\mathrm{Au})\end{array}$ & $\begin{array}{c}i_{2} \\
(\mathrm{Sn})\end{array}$ & $\begin{array}{c}i_{3} \\
(\mathrm{Ag}) \\
\end{array}$ & $\begin{array}{c}i_{4} \\
\text { (As) }\end{array}$ & $\begin{array}{c}i_{5} \\
(\mathrm{Sb}) \\
\end{array}$ & $\begin{array}{c}i_{6} \\
(\mathrm{Bi}) \\
\end{array}$ & $\begin{array}{c}i_{7} \\
\text { (Co) } \\
\end{array}$ & $\begin{array}{c}i_{8} \\
(\mathrm{Cu})\end{array}$ & $\begin{array}{c}i_{9} \\
\text { (La) } \\
\end{array}$ & $\begin{array}{c}i_{10} \\
(\mathrm{~Pb})\end{array}$ & $\begin{array}{c}i_{11} \\
(\mathrm{Zn})\end{array}$ & $\begin{array}{l}i_{12} \\
(W)\end{array}$ & $\begin{array}{c}i_{13} \\
(\mathrm{Mo})\end{array}$ & $\begin{array}{c}i_{14} \\
(\mathrm{Nb})\end{array}$ & $\begin{array}{c}i_{15} \\
\text { (Cd) }\end{array}$ \\
\hline 1 & HL & & & $\mathrm{HH}$ & $\mathrm{HH}$ & & & & $\mathrm{HH}$ & $\mathrm{HH}$ & $\mathrm{HH}$ & $\mathrm{HH}$ & $\mathrm{HH}$ & $\mathrm{HH}$ & $\mathrm{HH}$ \\
\hline 2 & & & LL & & $\mathrm{HH}$ & & $\mathrm{HH}$ & & HL & & & & & & \\
\hline 3 & & $\mathrm{HH}$ & & & LH & $\mathrm{HH}$ & LH & & & & & $\mathrm{HH}$ & & & \\
\hline 4 & $\mathrm{HH}$ & $\mathrm{HH}$ & & & $\mathrm{HH}$ & & & $\mathrm{HH}$ & & LH & & & & & $\mathrm{HH}$ \\
\hline 5 & & LL & LL & LL & & LL & LL & LL & $\mathrm{HH}$ & LL & & & & & LL \\
\hline 6 & & LL & LL & LL & LL & LL & & LL & & LL & LL & LL & LL & & LL \\
\hline$\ldots$ & $\ldots$ & $\ldots$ & $\ldots$ & $\ldots$ & $\ldots$ & $\ldots$ & $\ldots$ & $\ldots$ & $\ldots$ & $\ldots$ & $\ldots$ & $\ldots$ & $\ldots$ & $\ldots$ & $\ldots$ \\
\hline 4959 & & $\mathrm{HH}$ & $\mathrm{HH}$ & $\mathrm{HH}$ & $\mathrm{HH}$ & $\mathrm{HH}$ & $\mathrm{HH}$ & $\mathrm{HH}$ & LH & $\mathrm{HH}$ & $\mathrm{HH}$ & $\mathrm{HH}$ & $\mathrm{HH}$ & & $\mathrm{HH}$ \\
\hline
\end{tabular}


Table 9. Counts of items in local Moran's I clustering (LMIC) of elements.

\begin{tabular}{|c|c|c|c|c|c|}
\hline Element & Insignificant & High-high & Low-low & Low-high & High-low \\
\hline $\mathrm{Au}$ & 4023 & 113 & 466 & 163 & 194 \\
\hline Sn & 2584 & 300 & 1786 & 190 & 99 \\
\hline $\mathrm{Ag}$ & 1706 & 560 & 2286 & 336 & 71 \\
\hline As & 1931 & 521 & 2137 & 259 & 111 \\
\hline $\mathrm{Sb}$ & 1192 & 867 & 2509 & 305 & 86 \\
\hline $\mathrm{Bi}$ & 2352 & 351 & 1973 & 194 & 89 \\
\hline Co & 1810 & 981 & 1613 & 327 & 228 \\
\hline $\mathrm{Cu}$ & 2036 & 570 & 2044 & 169 & 140 \\
\hline $\mathrm{La}$ & 2025 & 659 & 1529 & 417 & 329 \\
\hline $\mathrm{Pb}$ & 3740 & 65 & 796 & 315 & 43 \\
\hline $\mathrm{Zn}$ & 1662 & 793 & 2049 & 200 & 255 \\
\hline $\mathrm{W}$ & 2442 & 332 & 1874 & 193 & 118 \\
\hline Mo & 2289 & 414 & 1952 & 128 & 176 \\
\hline $\mathrm{Nb}$ & 2749 & 478 & 1132 & 329 & 271 \\
\hline $\mathrm{Cd}$ & 2054 & 556 & 1927 & 303 & 119 \\
\hline
\end{tabular}

We used the Apriori algorithm to mine out dozens of association rules, of which 15 rules were selected for interpretation (Table 10). The supports for $\mathrm{Au}$ and $\mathrm{Pb}$ in the Apriori algorithm are smaller than the threshold, so no relevant association rules were mined. Meanwhile, the relevance of these association rules was judged according to the coexistence of elements and the geological environment in the study area.

Table 10. Mined association rules among elements.

\begin{tabular}{cccc}
\hline ID & Association rules & Support degree & Confidence \\
\hline a & $\{\mathrm{As}(\mathrm{HH})\} \Rightarrow\{\mathrm{Sb}(\mathrm{HH})\}$ & 0.076 & 0.73 \\
$\mathrm{~b}$ & $\{\mathrm{Cd}(\mathrm{HH})\} \Rightarrow\{\mathrm{Zn}(\mathrm{HH})\}$ & 0.090 & 0.81 \\
$\mathrm{c}$ & $\{\mathrm{W}(\mathrm{HH})\} \Rightarrow\{\mathrm{Cu}(\mathrm{HH})\}$ & 0.051 & 0.76 \\
$\mathrm{~d}$ & $\{\mathrm{Cu}(\mathrm{HH})\} \Rightarrow\{\mathrm{Co}(\mathrm{HH})\}$ & 0.089 & 0.77 \\
e & $\{\mathrm{Bi}(\mathrm{HH})\} \Rightarrow\{\mathrm{Cu}(\mathrm{HH})\}$ & 0.059 & 0.83 \\
$\mathrm{f}$ & $\{\mathrm{Mo}(\mathrm{HH})\} \Rightarrow\{\mathrm{Sb}(\mathrm{LL})\}$ & 0.065 & 0.77 \\
$\mathrm{~g}$ & $\{\mathrm{Zn}(\mathrm{HH}), \mathrm{Ag}(\mathrm{HH})\} \Rightarrow\{\mathrm{Cd}(\mathrm{HH})\}$ & 0.058 & 0.81 \\
$\mathrm{~h}$ & $\{\mathrm{Cd}(\mathrm{HH}), \mathrm{Ag}(\mathrm{HH})\} \Rightarrow\{\mathrm{Zn}(\mathrm{HH})\}$ & 0.058 & 0.92 \\
$\mathrm{i}$ & $\{\mathrm{Cd}(\mathrm{HH}), \mathrm{As}(\mathrm{HH})\} \Rightarrow\{\mathrm{Zn}(\mathrm{HH})\}$ & 0.053 & 0.93 \\
$\mathrm{j}$ & $\{\mathrm{As}(\mathrm{HH}), \mathrm{Zn}(\mathrm{HH})\} \Rightarrow\{\mathrm{Cd}(\mathrm{HH})\}$ & 0.053 & 0.82 \\
$\mathrm{k}$ & $\{\mathrm{Zn}(\mathrm{HH}), \mathrm{Sb}(\mathrm{HH})\} \Rightarrow\{\mathrm{Cd}(\mathrm{HH})\}$ & 0.055 & 0.71 \\
$\mathrm{l}$ & $\{\mathrm{Cd}(\mathrm{HH}), \mathrm{Sb}(\mathrm{HH})\} \Rightarrow\{\mathrm{Zn}(\mathrm{HH})\}$ & 0.055 & 0.93 \\
$\mathrm{~m}$ & $\{\mathrm{Zn}(\mathrm{HH}), \mathrm{As}(\mathrm{HH})\} \Rightarrow\{\mathrm{Sb}(\mathrm{HH})\}$ & 0.052 & 0.82 \\
$\mathrm{n}$ & $\{\mathrm{Cu}(\mathrm{HH}), \mathrm{La}(\mathrm{LL})\} \Rightarrow\{\mathrm{Co}(\mathrm{HH})\}$ & 0.052 & 0.76 \\
$\mathrm{o}$ & $\{\mathrm{Co}(\mathrm{HH}), \mathrm{Sb}(\mathrm{LL})\} \Rightarrow\{\mathrm{La}(\mathrm{LL})\}$ & 0.056 & 0.73 \\
\hline
\end{tabular}

$\mathrm{HH}$ (high-high clustered), LL (low-low clustered). 
The affinity of elements is the ability of elements to preferentially coexist with each other. The most abundant anions in the crustal system are oxygen (O) and sulfur (S), and the most abundant element that can exist as a natural metal is iron (Fe). Therefore, according to the geochemical affinities, the 15 elements are divided into the following three categories: (1) siderophile elements, i.e., $\mathrm{Au}$; (2) sulfophile elements, i.e., $\mathrm{Sn}, \mathrm{Ag}$, As, Sb, Bi, $\mathrm{Cu}, \mathrm{Co}, \mathrm{Pb}, \mathrm{Zn}$, and $\mathrm{Cd}$; and (3) oxyphile elements, i.e., Mo, Nb, W, and $\mathrm{La}$.

The mining of association rules shows that there are positive correlations among all sulfophile elements with $\mathrm{HH}$ clustering, that is, $\{\mathrm{As}(\mathrm{HH})\} \Rightarrow\{\mathrm{Sb}(\mathrm{HH})\},\{\mathrm{Cd}(\mathrm{HH})\} \Rightarrow\{\mathrm{Zn}$ $(\mathrm{HH})\},\{\mathrm{Cu}(\mathrm{HH})\} \Rightarrow\{\mathrm{Co}(\mathrm{HH})\},\{\mathrm{Bi}(\mathrm{HH})\} \Rightarrow\{\mathrm{Cu}(\mathrm{HH})\},\{\mathrm{Zn}(\mathrm{HH}), \mathrm{Ag}(\mathrm{HH})\} \Rightarrow\{\mathrm{Cd}(\mathrm{HH})\}$, $\{\mathrm{Cd}(\mathrm{HH}), \mathrm{Ag}(\mathrm{HH})\} \Rightarrow\{\mathrm{Zn}(\mathrm{HH})\},\{\mathrm{Cd}(\mathrm{HH}), \mathrm{As}(\mathrm{HH})\} \Rightarrow\{\mathrm{Zn}(\mathrm{HH})\},\{\mathrm{As}(\mathrm{HH}), \mathrm{Zn}(\mathrm{HH})\}$ $\Rightarrow\{\mathrm{Cd}(\mathrm{HH})\},\{\mathrm{Zn}(\mathrm{HH}), \mathrm{Sb}(\mathrm{HH})\} \Rightarrow\{\mathrm{Cd}(\mathrm{HH})\},\{\mathrm{Cd}(\mathrm{HH}), \mathrm{Sb}(\mathrm{HH})\} \Rightarrow\{\mathrm{Zn}(\mathrm{HH})\}$, and $\{\mathrm{Zn}$ $(\mathrm{HH}), \mathrm{As}(\mathrm{HH})\} \Rightarrow\{\mathrm{Sb}(\mathrm{HH})\}$. In rules $\{\mathrm{Mo}(\mathrm{HH})\} \Rightarrow\{\mathrm{Sb}(\mathrm{LL})\},\{\mathrm{Cu}(\mathrm{HH}), \mathrm{La}(\mathrm{LL})\} \Rightarrow\{\mathrm{Co}$ $(\mathrm{HH})\}$, and $\{\mathrm{Co}(\mathrm{HH}), \mathrm{Sb}(\mathrm{LL})\} \Rightarrow\{\mathrm{La}(\mathrm{LL})\}$, there are positive correlations between sulfophile elements with $\mathrm{HH}$ clustering and oxyphile elements with LL clustering.

We next compared the bivariate spatial cross-correlations and association rules for $\mathrm{Cu}$ and $\mathrm{Co}$ (Figure 11), and $\mathrm{As}$ and $\mathrm{Sb}$ (Figure 12). The distributions of $I_{\mathrm{CuCo}} \mathrm{HH}$ clustering and $I_{\mathrm{AsSb}} \mathrm{HH}$ clustering are spatially similar to the association rules $\{\mathrm{Cu}(\mathrm{HH})\} \Rightarrow\{\mathrm{Co}$ $(\mathrm{HH})\}$ and $\{\mathrm{As}(\mathrm{HH})\} \Rightarrow\{\mathrm{Sb}(\mathrm{HH})\}$, respectively; however, $I_{\mathrm{CuCo}} \mathrm{HH}$ clustering and $I_{\mathrm{AsSb}}$ $\mathrm{HH}$ clustering cover wider areas. In addition, $I_{\mathrm{CuCo}}$ and $I_{\mathrm{AsSb}}$ reveal not only high $\mathrm{HH}$ clustering but also LL, LH, and HL clustering, which shows the simultaneous relationship between two elements, but does not scale efficiently to massive data sets. In contrast, association rule mining is suitable for revealing the association among items in a large geochemical dataset.

(a)

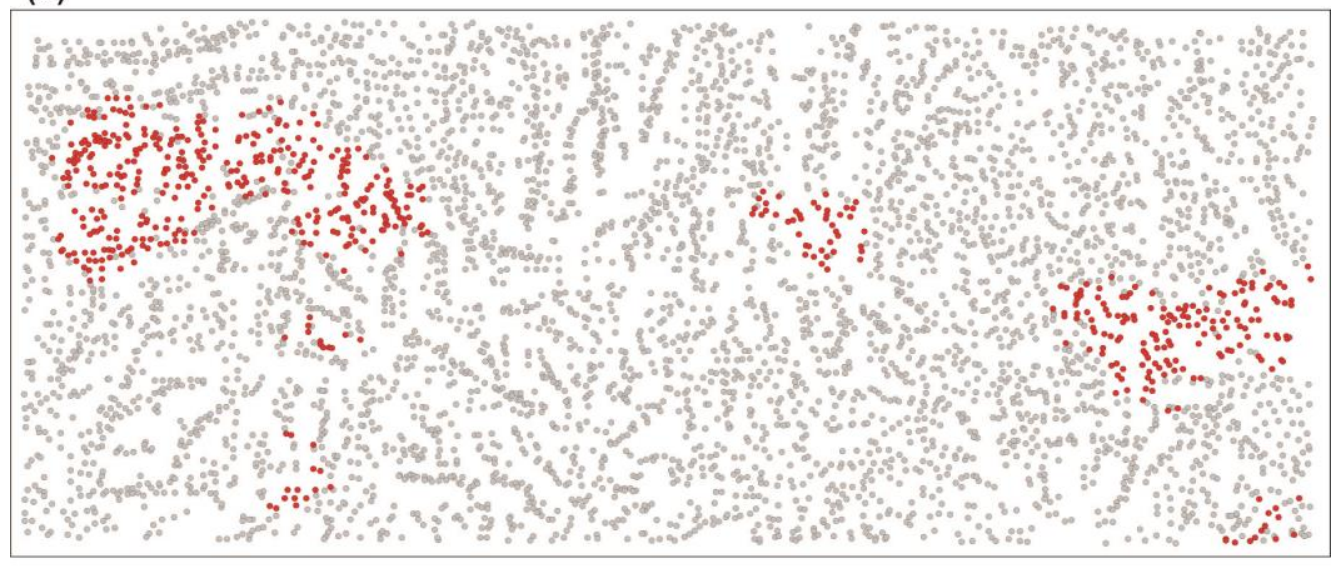

The mined rule points

Geochemical sampling points

(b)

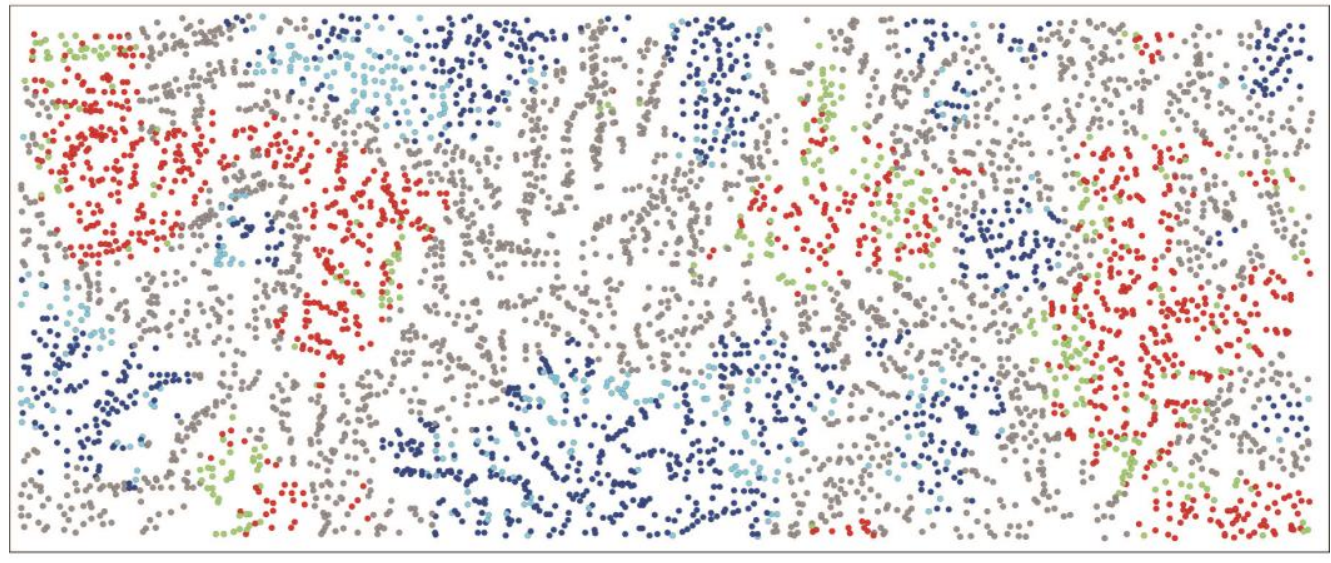


Figure 11. (a) Association rule mining result $\{\mathrm{Cu}(\mathrm{HH})\} \Rightarrow\{\mathrm{Co}(\mathrm{HH})\}$ and (b) bivariate spatial crosscorrelation indicator $I_{\mathrm{CuCo}}$ of $\mathrm{Cu}$ and $\mathrm{Co}$.

(a)

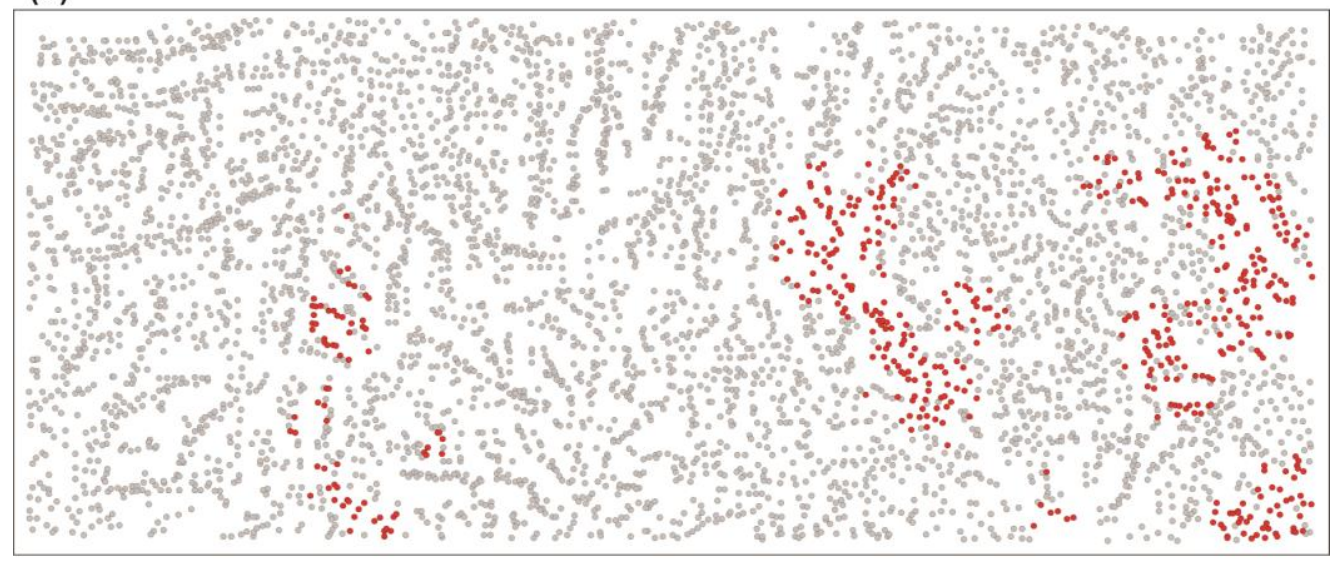

The mined rule points

Geochemical sampling points

(b)

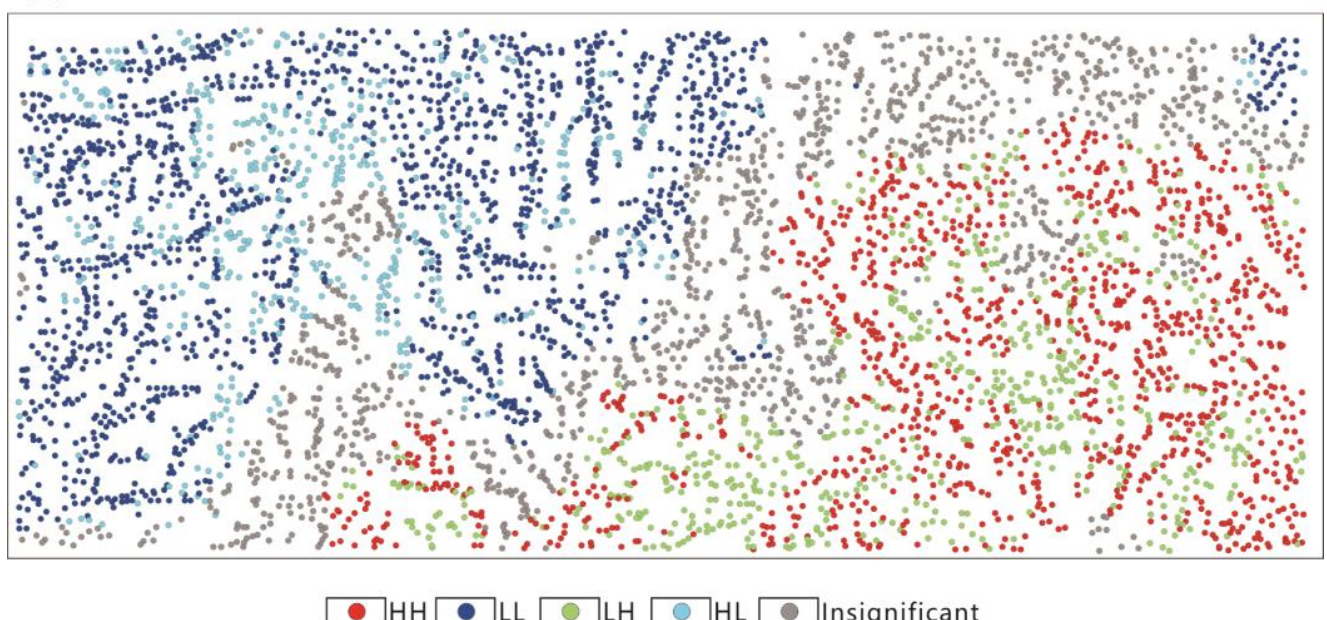

Figure 12. (a) Association rule mining result $\{\mathrm{As}(\mathrm{HH})\} \Rightarrow\{\mathrm{Sb}(\mathrm{HH})\}$ and (b) bivariate spatial crosscorrelation indicator $I_{\mathrm{AsSb}}$ of As and $\mathrm{Sb}$.

\subsubsection{Controls of geological features}

Due to the influence of multiple stages of tectonic and magmatic activities, the fault structures in the study area are relatively well developed. We calculated the Euclidean distance field for the faults in the study area (see Figure 13). Then, the 15 mined association rules were overlaid with the fault distance field (Figure 14). We found that more than $86 \%$ of the mined rule points are located within $1000 \mathrm{~m}$ distance of the fault, especially $\{\mathrm{Cu}$ $(\mathrm{HH})\} \Rightarrow\{\mathrm{Co}(\mathrm{HH})\}$ (Figure 15) and $\{\mathrm{Zn}(\mathrm{HH}), \mathrm{Sb}(\mathrm{HH})\} \Rightarrow\{\mathrm{Cd}(\mathrm{HH})\}$ (Figure 16). The rule $\{\mathrm{Cu}(\mathrm{HH})\} \Rightarrow\{\mathrm{Co}(\mathrm{HH})\}$ is most predominant near the faults in the northwest and southeast parts of the study area, and three known copper ore occurrences are also near the faults. The rule $\{\mathrm{Zn}(\mathrm{HH}), \mathrm{Sb}(\mathrm{HH})\} \Rightarrow\{\mathrm{Cd}(\mathrm{HH})\}$ is most strongly associated with the faults in the southeast part of the study area, and a known lead-zinc ore occurrence is near the faults. That is, the fault structure has an obvious control effect on clustering of the elements. In addition, we extracted streams and catchments area to analyze whether element co-occurrence is related to stream transport. As shown in Figures 17 and 18, most $\{\mathrm{Cu}(\mathrm{HH})\} \Rightarrow\{\mathrm{Co}(\mathrm{HH})\}$ and $\{\mathrm{Zn}(\mathrm{HH}), \mathrm{Sb}(\mathrm{HH})\} \Rightarrow\{\mathrm{Cd}(\mathrm{HH})\}$ events are distributed in the upper reaches of the streams and catchment areas, so the impact of stream transport on element association rule mining is weak in the study area. 


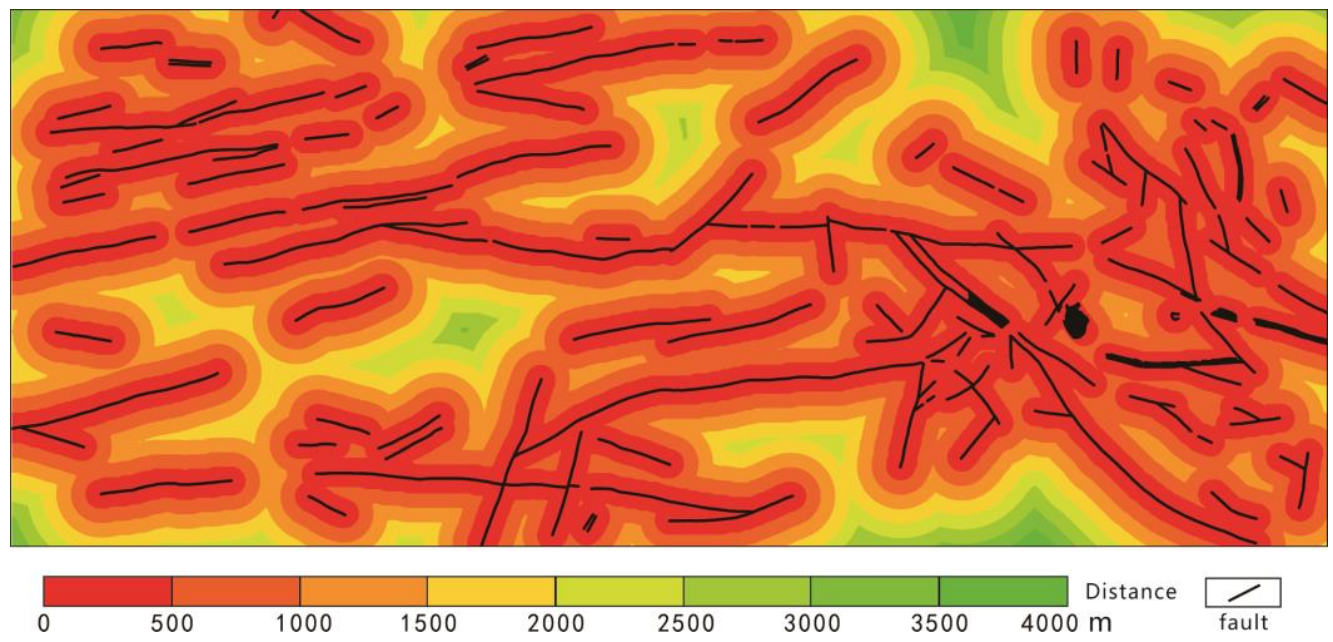

Figure 13. Euclidean distance field of faults.

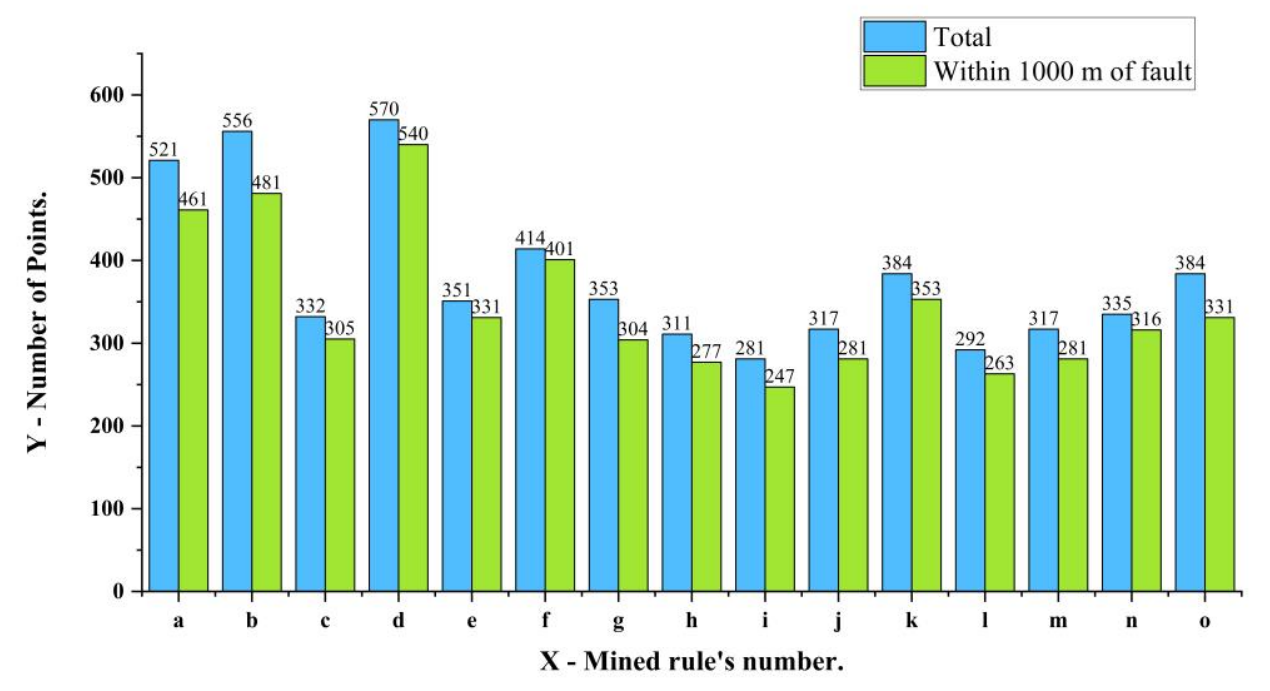

Figure 14. Numbers of mined rule points that are close to faults.

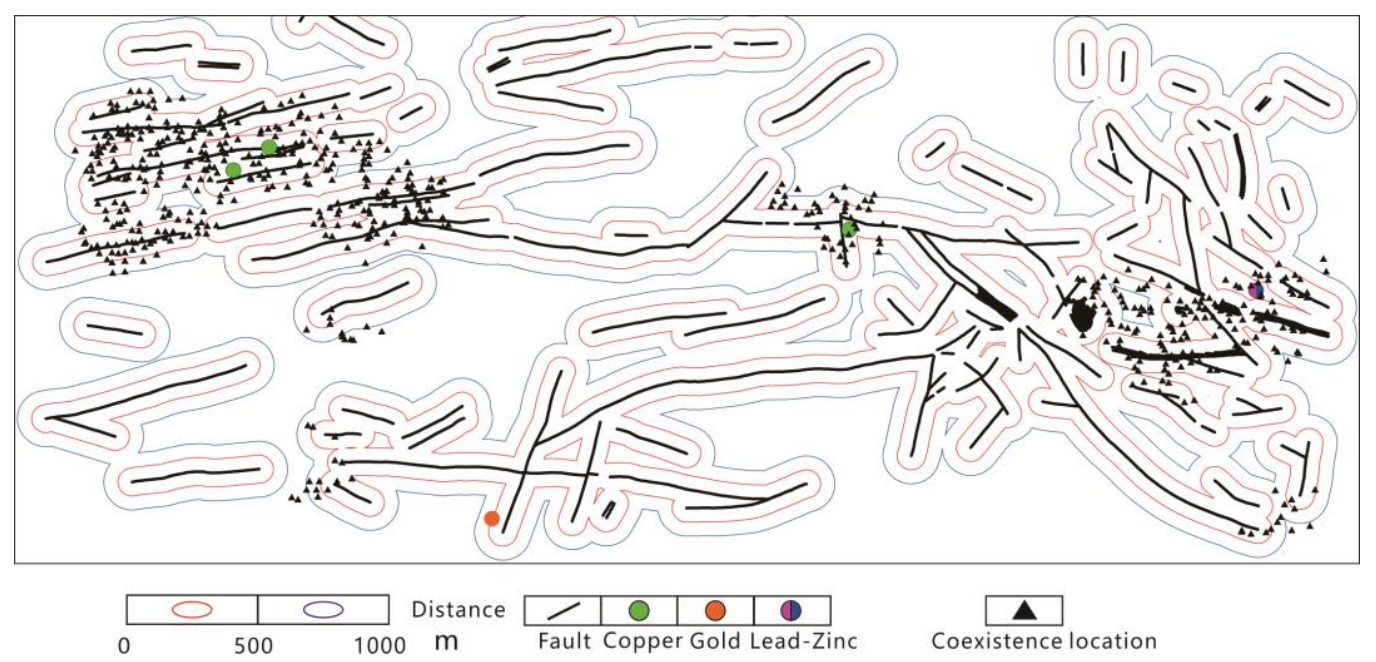

Figure 15. Rule $\{\mathrm{Cu}(\mathrm{HH})\} \Rightarrow\{\mathrm{Co}(\mathrm{HH})\}$ points within $500 \mathrm{~m}$ and $1000 \mathrm{~m}$ of faults. 


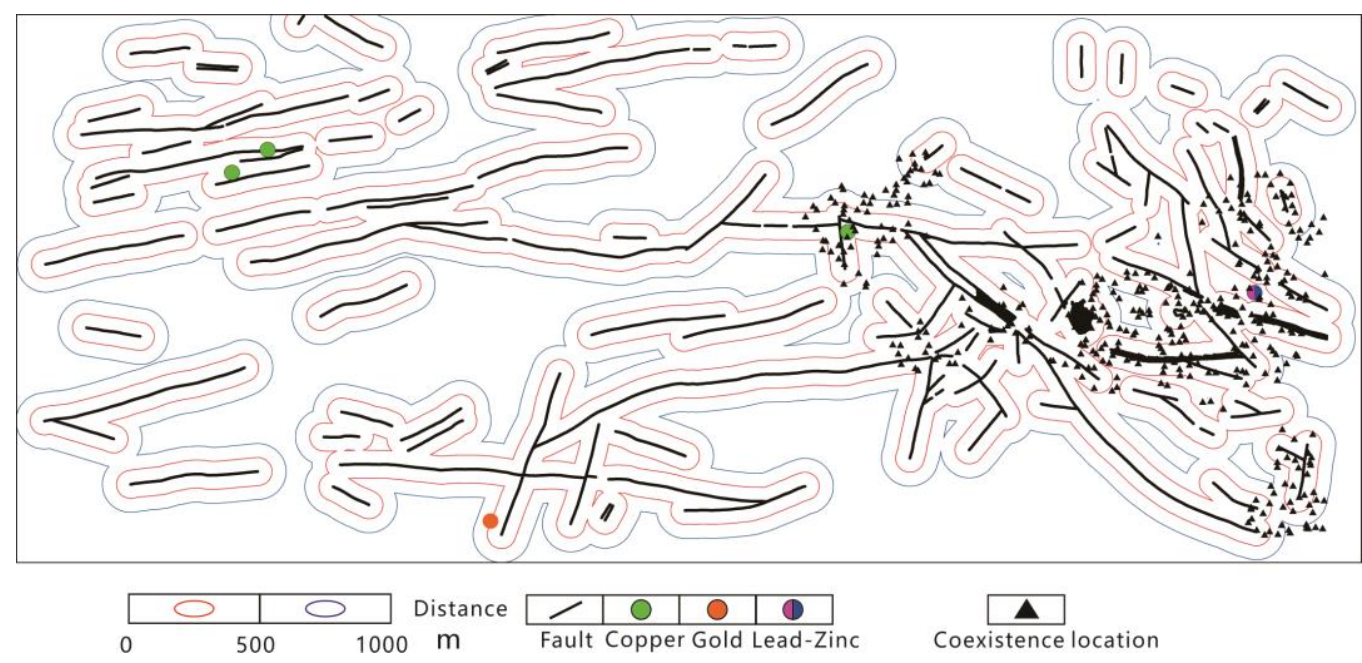

Figure 16. Rule $\{\mathrm{Zn}(\mathrm{HH}), \mathrm{Sb}(\mathrm{HH})\} \Rightarrow\{\mathrm{Cd}(\mathrm{HH})\}$ points within $500 \mathrm{~m}$ and $1000 \mathrm{~m}$ of faults.

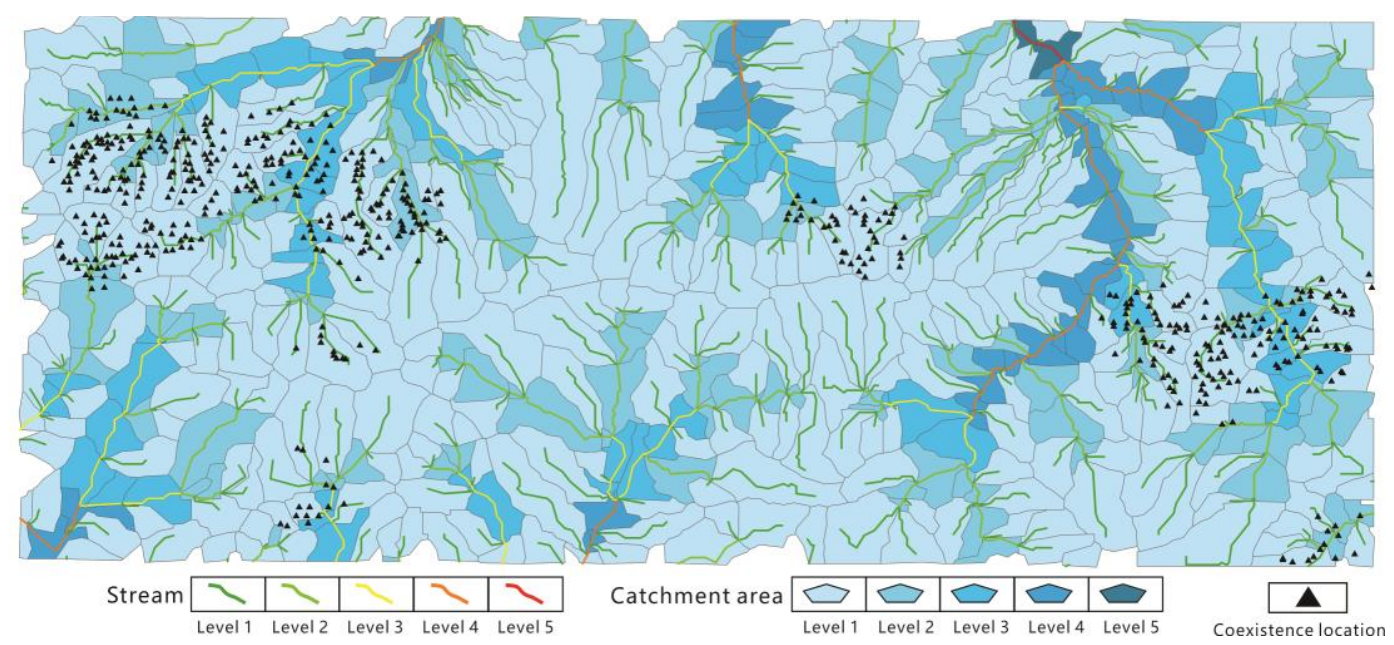

Figure 17. Rule $\{\mathrm{Cu}(\mathrm{HH})\} \Rightarrow\{\mathrm{Co}(\mathrm{HH})\}$ points overlayed with streams and catchments area.

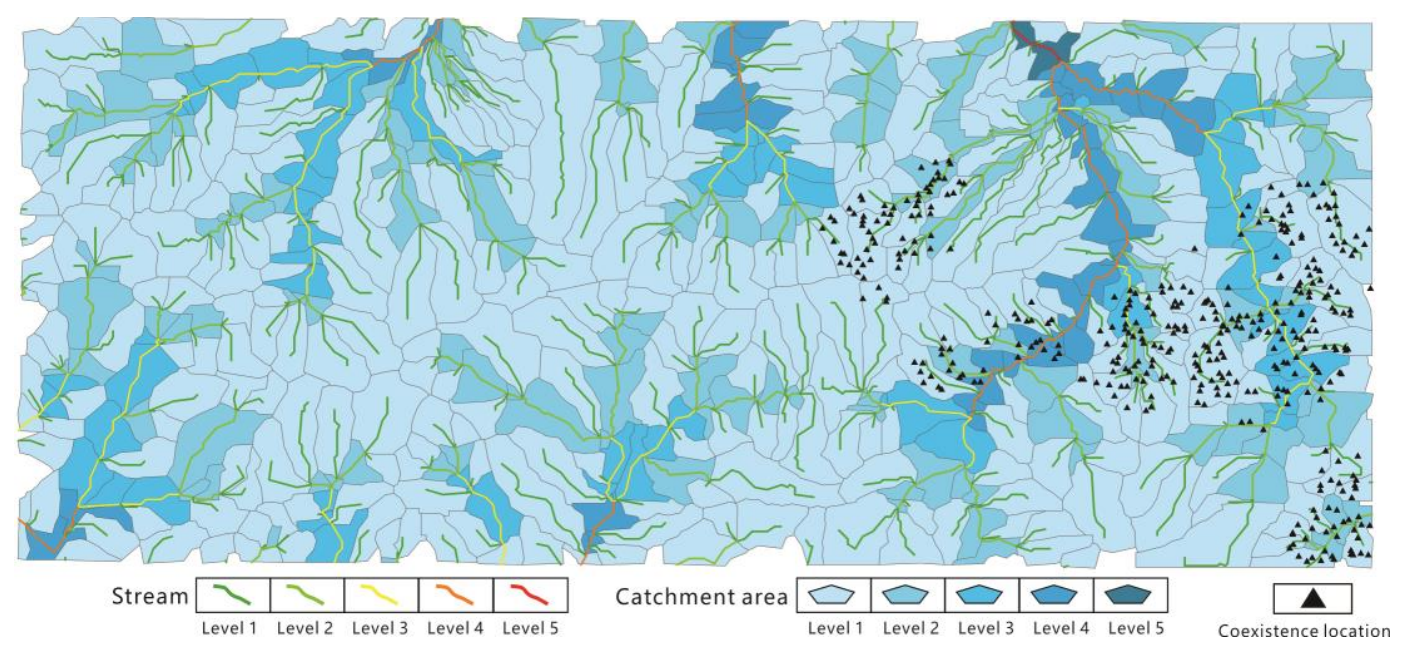

Figure 18. Rule $\{\mathrm{Zn}(\mathrm{HH}), \mathrm{Sb}(\mathrm{HH})\} \Rightarrow\{\mathrm{Cd}(\mathrm{HH})\}$ points overlayed with streams and catchments area. 
The mineralogical composition of lithological strata impacts the coexistence of elements. We overlaid the mined association rules with the geological map and counted the points and density of each rule in the main lithostrata (Figure 19). A greater density and number of points of association rules occur in the lower Proterozoic Baishahe Formation $\left(\mathrm{Pt}_{1} \mathrm{~b}\right)$ and the Variscan granodiorite $\left(\mathrm{P}_{1} \gamma \delta\right)$, especially $\{\mathrm{As}(\mathrm{HH})\} \Rightarrow\{\mathrm{Sb}(\mathrm{HH})\}$. The Baishahe Formation $\left(\mathrm{Pt}_{1} \mathrm{~b}\right)$ is the basement rock series in the study area. Due to the influence of multiple orogenic events and frequent magmatic activity, the lower Proterozoic Baishahe Formation $\left(\mathrm{Pt}_{1} \mathrm{~b}\right)$ and various intrusive rocks show good metallogenic conditions and prospects in the study area. Figure 20 shows that rule $\{\mathrm{As}(\mathrm{HH})\} \Rightarrow\{\mathrm{Sb}(\mathrm{HH})\}$ occurs not only in $\mathrm{Pt}$ b, but also in the contact zones between intrusive rocks of different ages and Ptib.

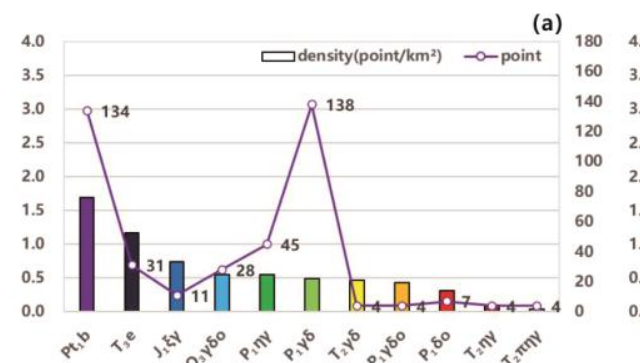

(d)
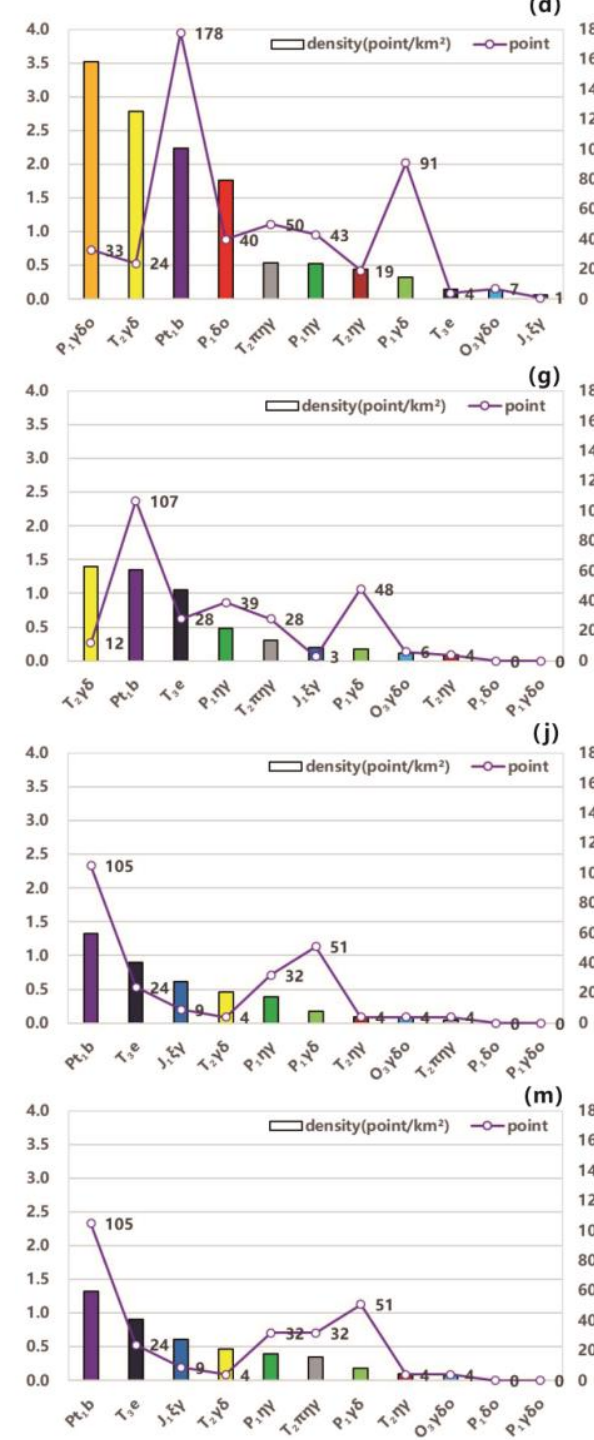

(b)
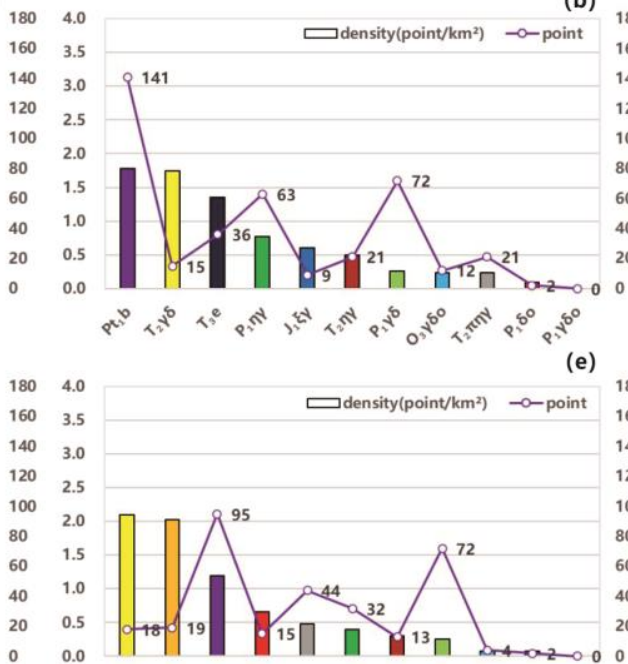

(g) $\quad \begin{array}{ll}180 & 4.0\end{array}$
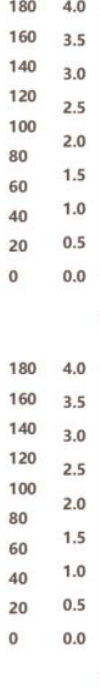

$180 \quad 4.0$

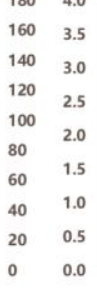

\begin{tabular}{ll}
160 & 3.5 \\
140 & 3.0 \\
120 & 2.5 \\
100 & 2.0 \\
80 & 1.5 \\
60 & 1.0 \\
40 & 1.0 \\
20 & 0.5 \\
0 & 0.0 \\
\hline
\end{tabular} (e)

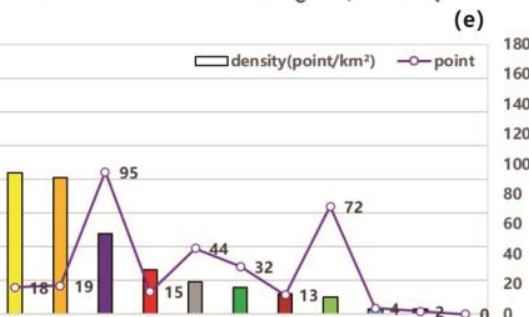

5.

(h)

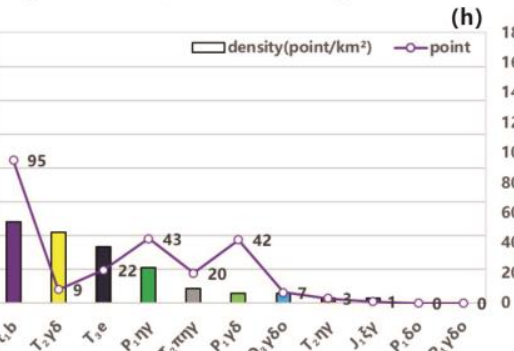

(k)

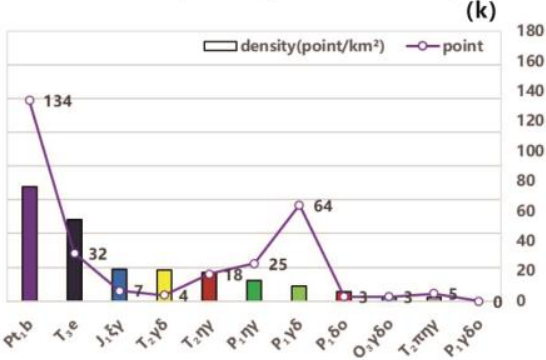

(n)

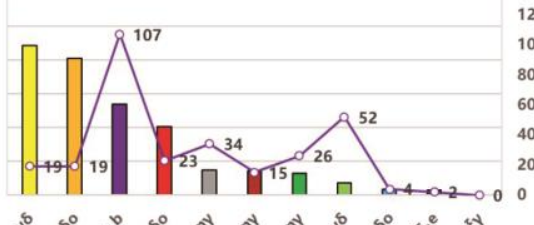

रा. (c) $\square$ density(point//km²) $\quad$ - - point 180

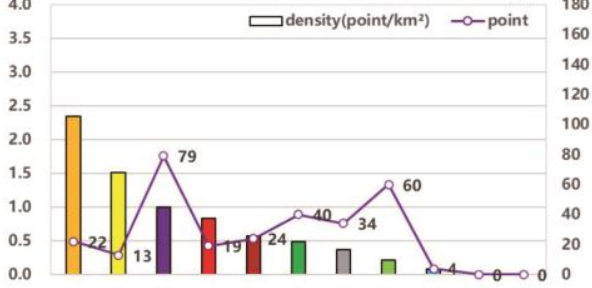

b.

(f)

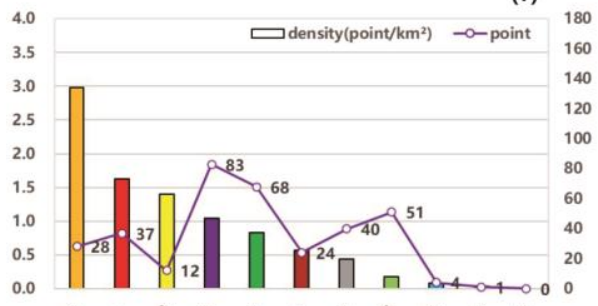

b.

(i) 180

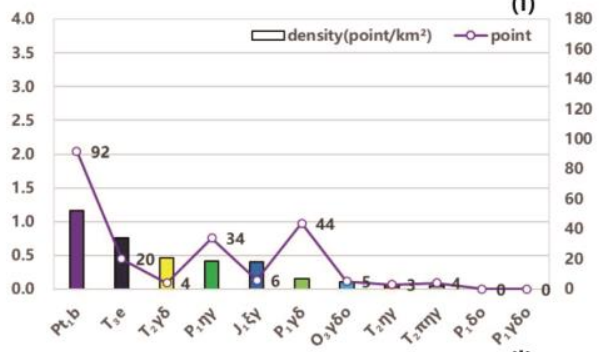

(I)

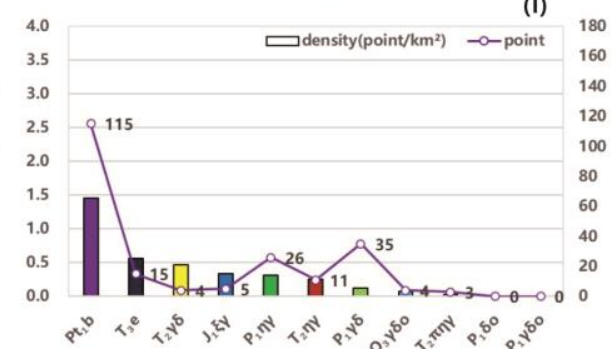

(o)

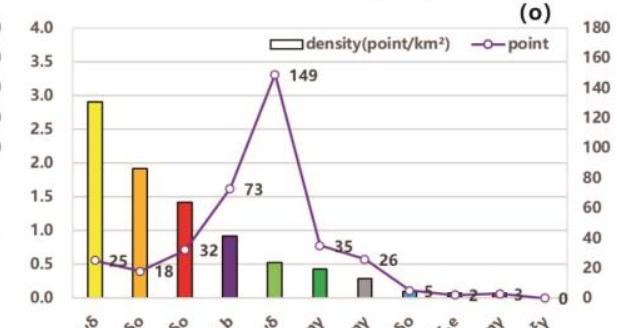

रु.

Figure 19. Total number of points and density of each mined rule, e.g., (a) $\{\mathrm{As}(\mathrm{HH})\} \Rightarrow\{\mathrm{Sb}(\mathrm{HH})\},(\mathrm{b})\{\mathrm{Cd}(\mathrm{HH})\} \Rightarrow\{\mathrm{Zn}(\mathrm{HH})\},(\mathrm{c})$ $\{\mathrm{W}(\mathrm{HH})\} \Rightarrow\{\mathrm{Cu}(\mathrm{HH})\},(\mathrm{d})\{\mathrm{Cu}(\mathrm{HH})\} \Rightarrow\{\mathrm{Co}(\mathrm{HH})\},(\mathrm{e})\{\mathrm{Bi}(\mathrm{HH})\} \Rightarrow\{\mathrm{Cu}(\mathrm{HH})\},(\mathrm{f})\{\mathrm{Mo}(\mathrm{HH})\} \Rightarrow\{\mathrm{Sb}(\mathrm{LL})\},(\mathrm{g})\{\mathrm{Zn}(\mathrm{HH}), \mathrm{Ag}(\mathrm{HH})\}$ 
$\Rightarrow\{\mathrm{Cd}(\mathrm{HH})\},(\mathrm{h})\{\mathrm{Cd}(\mathrm{HH}), \mathrm{Ag}(\mathrm{HH})\} \Rightarrow\{\mathrm{Zn}(\mathrm{HH})\},(\mathrm{i})\{\mathrm{Cd}(\mathrm{HH}), \mathrm{As}(\mathrm{HH})\} \Rightarrow\{\mathrm{Zn}(\mathrm{HH})\},(\mathrm{j})\{\mathrm{As}(\mathrm{HH}), \mathrm{Zn}(\mathrm{HH})\} \Rightarrow\{\mathrm{Cd}(\mathrm{HH})\},(\mathrm{k})$ $\{\mathrm{Zn}(\mathrm{HH}), \mathrm{Sb}(\mathrm{HH})\} \Rightarrow\{\mathrm{Cd}(\mathrm{HH})\},(\mathrm{l})\{\mathrm{Cd}(\mathrm{HH}), \mathrm{Sb}(\mathrm{HH})\} \Rightarrow\{\mathrm{Zn}(\mathrm{HH})\},(\mathrm{m})\{\mathrm{Zn}(\mathrm{HH}), \mathrm{As}(\mathrm{HH})\} \Rightarrow\{\mathrm{Sb}(\mathrm{HH})\},(\mathrm{n})\{\mathrm{Cu}(\mathrm{HH}), \mathrm{La}(\mathrm{LL})\}$ $\Rightarrow\{\mathrm{Co}(\mathrm{HH})\}$, and $(\mathrm{o})\{\mathrm{Co}(\mathrm{HH}), \mathrm{Sb}(\mathrm{LL})\} \Rightarrow\{\mathrm{La}(\mathrm{LL})\}$, in the main litho-strata.

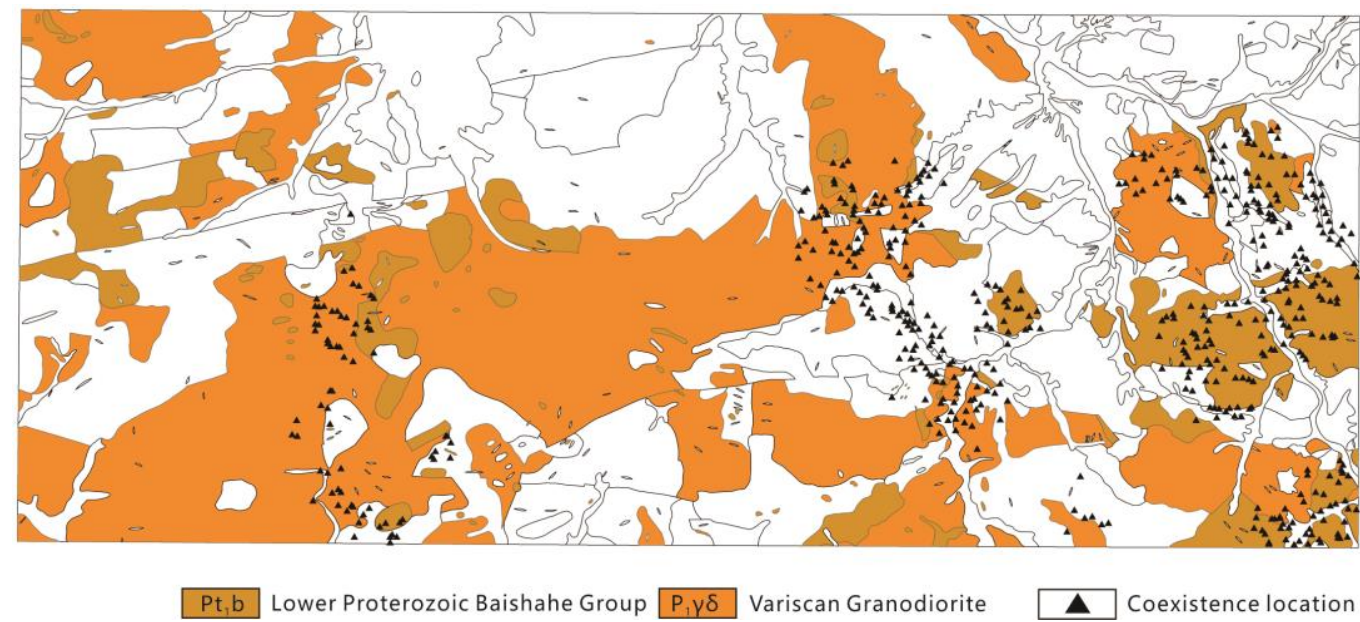

Figure 20. Rule $\{\mathrm{As}(\mathrm{HH})\} \Rightarrow\{\mathrm{Sb}(\mathrm{HH})\}$ overlayed with the main litho-strata.

According to the geological survey data, the enrichment of $\mathrm{Cu}, \mathrm{Pb}, \mathrm{Zn}, \mathrm{Ag}$, $\mathrm{Bi}$, and other elements in the lower Proterozoic Baishahe Formation ( $\left.\mathrm{Pt}_{1} \mathrm{~b}\right)$ provides the main oreforming materials in the study area. The locations of rules $\{\mathrm{As}(\mathrm{HH})\} \Rightarrow\{\mathrm{Sb}(\mathrm{HH})\},\{\mathrm{Zn}$ $(\mathrm{HH}), \mathrm{Ag}(\mathrm{HH})\} \Rightarrow\{\mathrm{Cd}(\mathrm{HH})\}$ and $\{\mathrm{Cu}(\mathrm{HH})\} \Rightarrow\{\mathrm{Co}(\mathrm{HH})\}$ are related to $\mathrm{Pt}_{1} \mathrm{~b}$, as shown in Figure 20, 21 and 22. The association rules of sulfophile elements, e.g., $\{\mathrm{As}(\mathrm{HH})\} \Rightarrow\{\mathrm{Sb}$ $(\mathrm{HH})\},\{\mathrm{Cd}(\mathrm{HH})\} \Rightarrow\{\mathrm{Zn}(\mathrm{HH})\},\{\mathrm{Zn}(\mathrm{HH}), \mathrm{Ag}(\mathrm{HH})\} \Rightarrow\{\mathrm{Cd}(\mathrm{HH})\},\{\mathrm{Cd}(\mathrm{HH}), \mathrm{Ag}(\mathrm{HH})\} \Rightarrow$ $\{\mathrm{Zn}(\mathrm{HH})\},\{\mathrm{Cd}(\mathrm{HH}), \mathrm{As}(\mathrm{HH})\} \Rightarrow\{\mathrm{Zn}(\mathrm{HH})\},\{\mathrm{Cd}(\mathrm{HH}), \mathrm{As}(\mathrm{HH})\} \Rightarrow\{\mathrm{Zn}(\mathrm{HH})\},\{\mathrm{Zn}(\mathrm{HH})$, $\mathrm{Sb}(\mathrm{HH})\} \Rightarrow\{\mathrm{Cd}(\mathrm{HH})\},\{\mathrm{Cd}(\mathrm{HH}), \mathrm{Sb}(\mathrm{HH})\} \Rightarrow\{\mathrm{Zn}(\mathrm{HH})\}$, and $\{\mathrm{Zn}(\mathrm{HH}), \mathrm{As}(\mathrm{HH})\} \Rightarrow\{\mathrm{Sb}$ $(\mathrm{HH})\}$, are mainly distributed in the lower Proterozoic Baishahe Formation ( $\mathrm{Pt} 1 \mathrm{~b})$, the upper Triassic Elashan Formation ( $\left.\mathrm{T}_{3} \mathrm{e}\right)$, and the Indosinian granodiorite $\left(\mathrm{T}_{2} \gamma \delta\right)$. Indosinian magmatism resulted in the intrusion of the middle Triassic Kekesai Sequence granite and the late Triassic Zamari Sequence granite, which provided conditions for enrichment of many sulfophile elements in the study area, especially represented by the rule $\{\mathrm{Zn}(\mathrm{HH})$, $\mathrm{Ag}(\mathrm{HH})\} \Rightarrow\{\mathrm{Cd}(\mathrm{HH})\}$ (Figure 21). Therefore, the Indosinian magmatism provided a heat and material source to enrich elements, and is an important geological unit for aggregating sulfophile elements. Cu mineralization often occurs in the contact between the Variscan magmatic rocks and surrounding rocks such as the Baishahe Formation ( $\left.\mathrm{Pt} \mathrm{t}_{1}\right)$, forming the Keregou East copper occurrence and the Hariza copper deposit. The rules of $\{\mathrm{W}$ $(\mathrm{HH})\} \Rightarrow\{\mathrm{Cu}(\mathrm{HH})\},\{\mathrm{Cu}(\mathrm{HH})\} \Rightarrow\{\mathrm{Co}(\mathrm{HH})\},\{\mathrm{Bi}(\mathrm{HH})\} \Rightarrow\{\mathrm{Cu}(\mathrm{HH})\},\{\mathrm{Cu}(\mathrm{HH}), \mathrm{La}(\mathrm{LL})\}$ $\Rightarrow\{\mathrm{Co}(\mathrm{HH})\},\{\mathrm{Co}(\mathrm{HH}), \mathrm{Sb}(\mathrm{LL})\} \Rightarrow\{\mathrm{La}(\mathrm{LL})\}$ related to $\mathrm{Cu} \mathrm{HH}$ and $\mathrm{Co} \mathrm{HH}$ clustering also have high density in the Variscan granite quartz diorite $\left(\mathrm{P}_{1} \gamma \delta \mathrm{o}\right)$, especially $\{\mathrm{Cu}(\mathrm{HH})\} \Rightarrow$ $\{\mathrm{Co}(\mathrm{HH})\}$ (Figure 22). Therefore, we may infer that a co-existing relationship between $\mathrm{Cu}$ and other elements developed in the Variscan granite quartz diorite. 


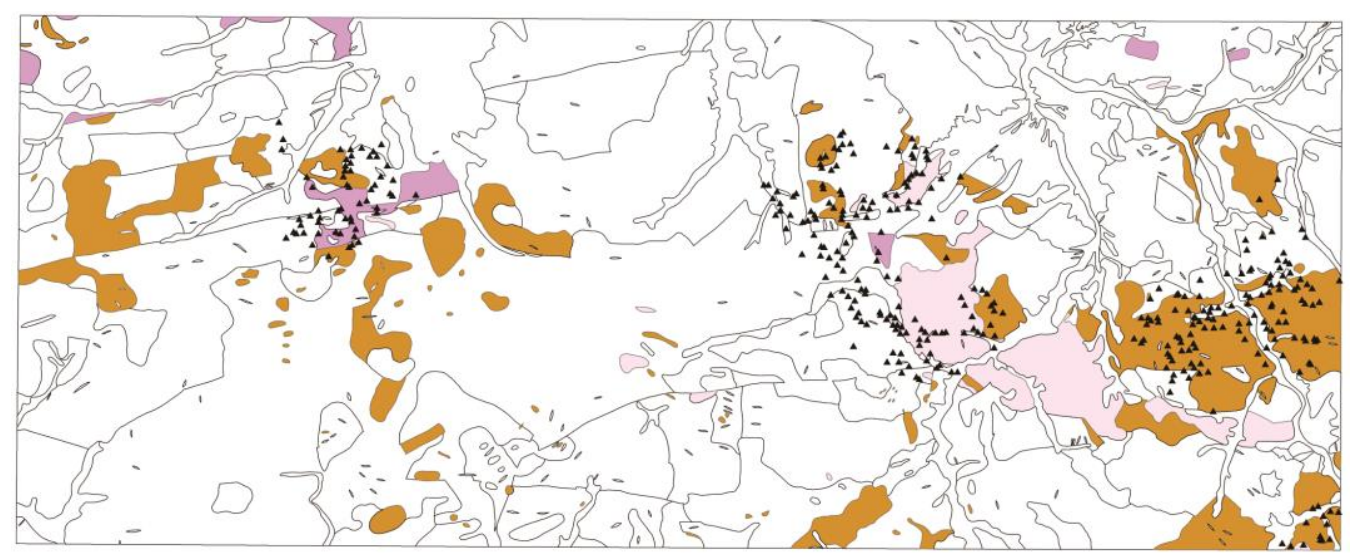

$\mathrm{Pt}_{1} \mathrm{~b}$ Lower Proterozoic Baishahe Group $\mathrm{T}_{2} \mathrm{\gamma}$ Indosinian Granodiorite Coexistence location

$\mathrm{T}_{3} \mathrm{e}$ Upper Triassic Elashan Group

Figure 21. Rule $\{\mathrm{Zn}(\mathrm{HH}), \mathrm{Ag}(\mathrm{HH})\} \Rightarrow\{\mathrm{Cd}(\mathrm{HH})\}$ overlayed with the main litho-strata.

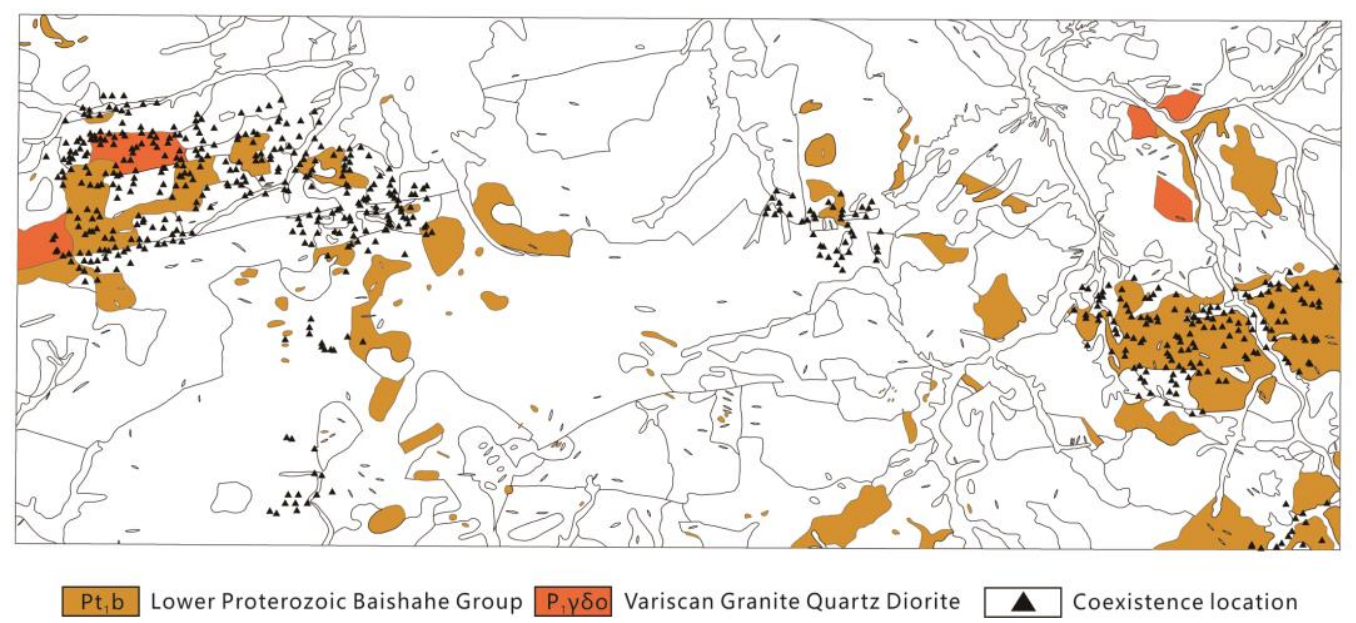

Figure 22. Rule $\{\mathrm{Cu}(\mathrm{HH})\} \Rightarrow\{\mathrm{Co}(\mathrm{HH})\}$ overlayed with the main litho-strata.

\section{Conclusions}

The case study of association rule mining in the Chahanwusu River area yields the following conclusions.

(1) According to the global auto-correlation indicators, Au shows a random distribution in the study area, and other 14 elements have positive correlations ranked from large to small are $\mathrm{Sb}, \mathrm{Zn}, \mathrm{Pb}, \mathrm{Cu}, \mathrm{Cd}, \mathrm{As}, \mathrm{Sn}, \mathrm{Bi}, \mathrm{Ag}, \mathrm{Mo}, \mathrm{Co}, \mathrm{W}, \mathrm{La}$, and $\mathrm{Nb}$. Compared with local Geary's C and local Getis-Ord's G, local Moran's I can identify points of HH, LL, LH and HL clustering with a precise meaning for each category, which makes it a better local auto-correlation indicator for association rule mining.

(2) Based on the univariate LMIC results, the proposed method successfully mined 15 association rules among various elements in the study area. Bivariate spatial crosscorrelation can also detect distribution pattern details of pair elements co-occurrence compared with association rule mining method. However, it cannot be used to efficiently explore massive geochemical datasets. In contrast, association rule mining can reveal the association among items in a large geochemical dataset.

(3) Overlying the mining results of association rules on the faults, ore occurrences and catchment areas, we found that more than $86 \%$ of the mined rule points are located within $1000 \mathrm{~m}$ of faults and near known ore occurrences, and the impact of stream transport on element co-occurrences is weak. Greater densities and numbers of points of association rules were found in the lower Proterozoic Baishahe Formation $\left(\mathrm{Pt}_{1} \mathrm{~b}\right)$ and the 
Variscan granodiorite $\left(\mathrm{P}_{1} \gamma \delta\right)$. Therefore, the association rules are closely related to specific geological features.

The association rules mined in this paper are mainly high-value element co-occurrence. Where these combinations appear, higher concentration of the element is more likely, which can improve the prediction of unknown ore deposits or occurrences. However, the mining efficiency of low-value element co-occurrence is low and the local dilution of elements in the study area cannot be effectively detected. In the future, we will build an element association rule database to find combinations of anomalies for known metallogenic elements and to map the probability of unknown mineralization in the study area.

Author Contributions: Conceptualization, B.Z. and J.D.; methodology, Y.C.; software, Z.J. and N.C.; validation, B.Z., Z.J., and Y.C.; data curation, Y.C.; writing - original draft preparation, B.Z. and Z.J.; writing-review and editing, B.Z. and U.K.; funding acquisition, B.Z. All authors have read and agreed to the published version of the manuscript.

Funding: This study was supported by grants from the National Natural Science Foundation of China (Grant Nos. 42072326 and 41772348), China Geological Survey Project (Grant No. DD20190156), and the National Key Research and Development Program of China (Grant No. 2019YFC1805905).

Acknowledgments: The authors would like to thank the Co-Construction MapGIS Library by Engineering Research Center for Geographic Information System of China and Central South University for providing MapGIS® software. We also thank senior engineer Professor ZHANG Shao-ning (The 8th Team of Qinghai Provincial Bureau of Nonferrous Metals and Geological Exploration), Professor LAI Jian-qing (Central South University) for their kind assistance with data collection and Professor Jeffrey Dick (Central South University) for revising scientific-English writing of the article.

Conflicts of Interest: The authors declare no conflict of interest.

\section{References}

1. Korobova, E.M.; Romanov, S.L. A Chernobyl 137Cs contamination study as an example for the spatial structure of geochemical fields and modeling of the geochemical field structure. Chemometrics and Intelligent Laboratory Systems 2009, 99, 1-8.

2. Zhang, B.; Chen, Y.; Huang, A.; Lu, H.; Cheng, Q. Geochemical field and its roles on the 3D prediction of concealed ore-bodies. Acta Petrologica Sinica 2018, 34, 352-362.

3. Tobler, W.R. A computer movie simulating urban growth in the Detroit region. Economic geography 1970, 46, $234-240$.

4. Moran, P.A. Notes on continuous stochastic phenomena. Biometrika 1950, 37, 17-23.

5. Geary, R.C. The Contiguity Ratio and Statistical Mapping. Incorporated Statian 1954, 5, 115-146.

6. Cliff, A.D.; Ord, J.K. The Problem of Spatial Autocorrelation. Regional Science 1969, 1, $26-55$.

7. Cliff, A.D.; Ord, J.K. Evaluating the percentage points of a spatial autocorrelation coefficient. Geographical Analysis 1971, 3, 5162.

8. Cliff, A.D.; Ord, J.K. Spatial processes: models \& applications; Taylor \& Francis: 1981.

9. Getis, A.; Ord, J.K. The Analysis of Spatial Association by Use of Distance Statistics; Springer: 2010; pp. 127-145.

10. Ord, J.K.; Getis, A. Local spatial autocorrelation statistics: distributional issues and an application. Geographical analysis 1995, 27, 286-306.

11. Anselin, L. Local indicators of spatial association -LISA. Geographical analysis 1995, 27, 93-115.

12. Boots, B.; Okabe, A. Local statistical spatial analysis: Inventory and prospect. International Journal of Geographical Information Science 2007, 21, 355-375.

13. Anselin, L. A local indicator of multivariate spatial association: extending Geary's C. Geographical Analysis 2019, 51, 133-150. 
14. Goovaerts, P.; Jacquez, G.M. Accounting for regional background and population size in the detection of spatial clusters and outliers using geostatistical filtering and spatial neutral models: the case of lung cancer in Long Island, New York. International Journal of Health Geographics 2004, 3, 14.

15. McLaughlin, C.C.; Boscoe, F.P. Effects of randomization methods on statistical inference in disease cluster detection. Health $\mathcal{E}$ place 2007, 13, 152-163.

16. Yu, X.; Wang, S.; Wang, H.; Liang, Y.; Chen, S.; Wu, K.; Yang, Z.; Li, C.; Chang, Y.; Zhan, Y. Detection of Geochemical Element Assemblage Anomalies Using a Local Correlation Approach. Journal of Earth Science 2021, 32, 408-414.

17. Xiao, G.; Hu, Y.; Li, N.; Yang, D. Spatial autocorrelation analysis of monitoring data of heavy metals in rice in China. Food Control 2018, 89, 32-37.

18. Bivand, R.S.; Wong, D.W. Comparing implementations of global and local indicators of spatial association. Test 2018, 27, 716748.

19. Cheng, Q. Singularity theory and methods for mapping geochemical anomalies caused by buried sources and for predicting undiscovered mineral deposits in covered areas. Journal of Geochemical Exploration 2012, 122, 55-70.

20. Carranza, E.J.M. Geochemical anomaly and mineral prospectivity mapping in GIS; Elsevier: 2008.

21. Zuo, R.; Xiong, Y. Geodata science and geochemical mapping. Journal of Geochemical Exploration 2019, $209,106431$.

22. Wang, J.; Zhou, Y.; Xiao, F. Identification of multi-element geochemical anomalies using unsupervised machine learning algorithms: A case study from Ag-Pb-Zn deposits in north-western Zhejiang, China. Applied Geochemistry 2020, 120, 104679.

23. Taylor, R.; Steven, T. Definition of mineral resource potential. Economic Geology 1983, 78, 1268-1270.

24. Wang, L.; Wu, X.; Zhang, B.; Li, X.; Huang, A.; Meng, F.; Dai, P. Recognition of Significant Surface Soil Geochemical Anomalies Via Weighted 3D Shortest-Distance Field of Subsurface Orebodies: A Case Study in the Hongtoushan Copper Mine, NE China. Natural Resources Research 2019, 28, 587-607.

25. Hawkes, H.E.; Webb, J.S. Geochemistry in mineral exploration. Soil Science 1963, 95, 283.

26. Sinclair, A. Selection of threshold values in geochemical data using probability graphs. Journal of Geochemical Exploration 1974, 3, 129-149.

27. Govett, G.; Goodfellow, W.; Chapman, R.; Chork, C. Exploration geochemistry-distribution of elements and recognition of anomalies. Journal of the International Association for Mathematical Geology 1975, 7, 415-446.

28. El-Makky, A.M. Statistical analyses of $\mathrm{La}, \mathrm{Ce}, \mathrm{Nd}, \mathrm{Y}, \mathrm{Nb}, \mathrm{Ti}, \mathrm{P}$, and $\mathrm{Zr}$ in bedrocks and their significance in geochemical exploration at the Um Garayat Gold mine area, Eastern Desert, Egypt. Natural resources research 2011, $20,157$.

29. Ravani, P.; Barrett, B.J.; Parfrey, P.S. Longitudinal Studies 2: Modeling Data Using Multivariate Analysis. Methods in molecular biology (Clifton, NJ) 2021, 2249, 103-124.

30. Cox, D.R.; Snell, E.J. Analysis of binary data; Routledge: 2018.

31. Cioci, A.C.; Cioci, A.L.; Mantero, A.M.; Parreco, J.P.; Yeh, D.D.; Rattan, R. Advanced statistics: Multiple logistic regression, Cox proportional hazards, and propensity scores. Surgical Infections 2021, 22, 604-610.

32. Agterberg, F.P. Computer programs for mineral exploration. Science 1989, 245, 76-81.

33. Cheng, Q.; Agterberg, F. Fuzzy weights of evidence method and its application in mineral potential mapping. Natural resources research 1999, 8, 27-35.

34. Goyes-Penafiel, P.; Hernandez-Rojas, A. Double landslide susceptibility assessment based on artificial neural networks and weights of evidence. Boletin De Geologia 2021, 43, 173-191.

35. Cheng, Q.; Agterberg, F.; Ballantyne, S. The separation of geochemical anomalies from background by fractal methods. Journal of Geochemical Exploration 1994, 51, 109-130.

36. Cheng, Q.; Xu, Y.; Grunsky, E. Integrated spatial and spectrum method for geochemical anomaly separation. Natural Resources Research 2000, 9, 43-52. 
37. Cheng, Q. Mapping singularities with stream sediment geochemical data for prediction of undiscovered mineral deposits in Gejiu, Yunnan Province, China. Ore Geology Reviews 2007, 32, 314-324.

38. Goovaerts, P. Geostatistical modelling of spatial uncertainty using p-field simulation with conditional probability fields. International Journal of Geographical Information Science 2002, 16, 167-178.

39. Naik, M.R.; Barik, M.; Prasad, K.; Kumar, A.; Verma, A.K.; Sahoo, S.K.; Jha, V.; Sahoo, N.K. Hydro-geochemical analysis based on entropy and geostatistics model for delineation of anthropogenic ground water pollution for health risks assessment of Dhenkanal district, India. Ecotoxicology 2021, 2, 1-16.

40. Zuo, R.; Carranza, E.J.M. Support vector machine: a tool for mapping mineral prospectivity. Computers $\mathcal{E}$ Geosciences 2011, 37, 1967-1975.

41. Xiong, J.; Li, J.; Cheng, W.; Wang, N.; Guo, L. A GIS-based support vector machine model for flash flood vulnerability assessment and mapping in China. ISPRS International Journal of Geo-Information 2019, 8, 297.

42. Rodriguez-Galiano, V.; Chica-Olmo, M.; Chica-Rivas, M. Predictive modelling of gold potential with the integration of multisource information based on random forest: a case study on the Rodalquilar area, Southern Spain. International Journal of Geographical Information Science 2014, 28, 1336-1354.

43. Zhang, B.; Li, M.; Li, W.; Jiang, Z.; Khan, U.; Wang, L.; Wang, F. Machine learning strategies for lithostratigraphic classification based on geochemical sampling data: a case study in the area of the Chahanwusu River, Qinghai Province, China. Journal of Central South University 2021, 28, 1422-1447.

44. Porwal, A.; Carranza, E.J.M. Classifiers for modeling of mineral potential; Wiley-Blackwell: 2008.

45. Porwal, A.; Carranza, E.J.M.; Hale, M. Bayesian network classifiers for mineral potential mapping. Computers E Geosciences 2006, $32,1-16$.

46. Klüppelberg, C.; Krali, M. Estimating an extreme Bayesian network via scalings. Journal of Multivariate Analysis 2021, $181,104672$.

47. Xiong, Y.; Zuo, R. Recognition of geochemical anomalies using a deep autoencoder network. Computers $\mathcal{E}$ Geosciences 2016, 86, 75-82.

48. Nguyen, T.T.; Liu, X.; Ren, Z. A study of geochemical exploration spational cluster identification based on local spatial autocorrelation. Geographical E Geochemical Exploration 2014, 38, 370-376.

49. Wang, H.; Cheng, Q.; Zuo, R. Spatial characteristics of geochemical patterns related to Fe mineralization in the southwestern Fujian province (China). Journal of Geochemical Exploration 2015, 148, 259-269.

50. Ji, b.; Zhou, T.; Yuan, F.; Zhang, D.; Liu, L.; Liu, G. A method for identifying geochemical anomalies based on spatial autocorrelation. Science of Surveying and Mapping 2017, 42, 24-27+123.

51. Sadeghi, M.; Morris, G.A.; Carranza, E.J.M.; Ladenberger, A.; Andersson, M. Rare earth element distribution and mineralization in Sweden: an application of principal component analysis to FOREGS soil geochemistry. Journal of Geochemical Exploration 2013, $133,160-175$.

52. Wang, J.; Zuo, R. Quantifying the Distribution Characteristics of Geochemical Elements and Identifying Their Associations in Southwestern Fujian Province, China. Minerals 2020, 10, 183.

53. Zhang, C.-S.; Li, Y. Extension of local association rules mining algorithm based on apriori algorithm. In Proceedings of the 2014 5th IEEE International Conference on Software Engineering and Service Science (ICSESS), 2014; pp. 340-343.

54. Zhang, X. Study of an improved Apriori algorithm for data mining of association rules. In Proceedings of the International Conference on Applied Science \& Engineering Innovation, 2015.

55. Xu, T.; Dong, X. Mining frequent patterns with multiple minimum supports using basic Apriori. In Proceedings of the 2013 Ninth International Conference on Natural Computation (ICNC), 2013; pp. 957-961.

56. Wu, X.; Kumar, V.; Quinlan, J.R.; Ghosh, J.; Yang, Q.; Motoda, H.; McLachlan, G.J.; Ng, A.; Liu, B.; Philip, S.Y. Top 10 algorithms in data mining. Knowledge and information systems 2008, 14, 1-37. 
57. Agrawal, R.; Imieliński, T.; Swami, A. Mining association rules between sets of items in large databases. In Proceedings of the Proceedings of the 1993 ACM SIGMOD international conference on Management of data, 1993; pp. 207-216.

58. Liu, X.; Zhou, Y. Application of association rule algorithm in studying abnormal elemental associations in the Pangxidong area in western Guangdong Province,China. Earth Science Frontiers 2019, 26, 57-71.

59. Tang, J.; JI, B.; Yan, Y. Comprehensive survey report of 1:50000 regional mineral geology, stream sediment geochemistry and high-precision magnetic survey in the Chahanwusu River area, Dulan County, Qinghai Province. 2008, 254-273.

60. Chou, Y.H. Spatial pattern and spatial autocorrelation. In Proceedings of the International Conference on Spatial Information Theory, 1995; pp. 365-376.

61. Buja, A.; Cook, D.; Swayne, D.F. Interactive high-dimensional data visualization. Journal of computational and graphical statistics 1996, 5, 78-99.

62. Anselin, L.; Syabri, I.; Smirnov, O. Visualizing multivariate spatial correlation with dynamically linked windows. In Proceedings of the Proceedings, CSISS Workshop on New Tools for Spatial Data Analysis, Santa Barbara, CA, 2002. 